\title{
Why Are (Some) Consumers (Finally) Writing Fewer Checks? The Role of Payment Characteristics
}

\author{
Scott Schuh and Joanna Stavins* \\ Federal Reserve Bank of Boston
}

December 2007

\begin{abstract}
Since the mid-1990s, the U.S. payment system has been undergoing a paper-toelectronics transformation featuring a significant decline in the number of paper checks written for payment. The timing and magnitude of the transformation have been surprising, and the future direction of payments is quite uncertain, largely because of a lack of data and research that explain why agents choose payment instruments. Using data from new surveys on consumer payment behavior, this paper shows that the large and relatively sudden decline in aggregate check use is not spread evenly among consumers despite the widespread availability of cheaper, more convenient, and better-timed electronic alternatives. Fundamental characteristics of payment instruments - cost, convenience, payment timing, and the like - are much more important determinants of payment choice than demographics or determinants of money demand, and these characteristics raise the cross-section explanatory power of econometric models of payment demand by three-fold or more.
\end{abstract}

* 600 Atlantic Avenue, Boston, MA 02210. Schuh: Scott.Schuh@bos.frb.org, (617) 973-3941; Stavins: Joanna.Stavins@bos.frb.org, (617) 973-4217. We thank David DeRemer, Benjamin Levinger, Charles Sprenger, and Caroline Theoharides for excellent research assistance, and David Brown and Marcella Vencil-Wiegand for assistance with implementing the Federal Reserve consumer payment survey and managing the data. Sharon Hermanson and the AARP kindly provided data from the AARP consumer payment survey. The views and opinions expressed in this paper are those of the authors and do not necessarily represent the views of the Federal Reserve Bank of Boston, the Board of Governors of the Federal Reserve System, or the AARP. 


\section{Introduction}

Paper check use in the United States (finally) is declining - at least for (some) consumers. After a long history of steady increase, the volume of U.S. checks began to contract in the mid1990s, falling about 38 percent between 1995 and 2006 (Gerdes and Walton 2002 and 2005, Federal Reserve System 2007). However, during the last three years of that period (2003-2006) - while aggregate volume was falling 16 percent - only 31 percent of U.S. consumers reduced their use of checks, and a scant 0.4 percent stopped using checks entirely. In fact, during this era of supposed check demise, 19 percent of consumers actually increased their use of checks. At the same time, the aggregate adoption and use of newer electronic payment methods are rapidly increasing. This phenomenon often referred to as the "paper-to-electronics transformation," or "payments transformation” for short. ${ }^{1}$

In a sense, the payments transformation is not particularly surprising. Indeed, a decline in check use had been predicted at least since the 1960s, and the Federal Reserve Bank of Atlanta (1983, p. 5) declared, "Between 1989 and 1994, personal check volume should decline sharply..." Although the timing of these predictions was off, the payment transformation itself was largely inevitable because the transportation, processing, and settlement of paper checks is very expensive and slow - disadvantages that became increasingly severe as the information technology revolution unfolded.

Nevertheless, many aspects of the payment transformation and its implications for consumer payment choice are not well understood. Why did check volume begin to decline in the mid-1990s and not earlier (or later)? Why did check volume decline as much as it did, rather than faster or slower? How much more will it decline in the coming years? And why are only one-third of U.S. consumers writing so many fewer checks but most are still clinging to checks? In particular, given that checks are so costly relative to other payment methods, why do they continue to be used so widely for payment? ${ }^{2}$ Answers to these and related questions have important implications for the Federal Reserve and the U.S. payment system. The decline in

\footnotetext{
${ }^{1}$ Cash (currency and coins) often is included in characterizations of this transformation, but there is even less evidence on the use of cash than the use of checks.

${ }^{2}$ Garcia Swartz, Hahn and Layne-Farrar (2004) suggest that the marginal cost to consumers is highest for cash and check, while marginal benefits are similar across payment methods. Social marginal costs of checks and cash have also been estimated to exceed those of credit or debit cards (Hancock and Humphrey 1998).
} 
check volume has severely affected Federal Reserve business operations, reducing processing sites by 51 percent and total employment by 15 percent (Benton, Blair, Crowe, and Schuh 2007).

One key reason the payment transformation is not well understood is because there is very little research on consumer behavior and payment choice (Schreft 2005). ${ }^{3}$ For example, fewer than 5 percent of entries in the "Consumer Payment Bibliography" by the Federal Reserve Bank of Philadephia (2006) contained studies with theories or empirical work on consumer payment demand; most entries focused more on the supply of payments. In addition, not much data on consumer payment behavior are readily available to the public either (Carten, Littman, Schuh, and Stavins 2007). Since the payment transformation began, some data and analysis have emerged - such as the payment studies by the Federal Reserve (Gerdes and Walton 2002, Gerdes, Liu, Parke and Walton 2005) - that have contributed to improved understanding of how consumers pay. But much less is understood about why they choose their payments instruments. This paper studies consumer payment choice by estimating reduced-form econometric models of payment demand for a wide variety of common payment methods using a rich new data source. Following common practice in the literature, we specify models of payment adoption (extensive margin) and payment use (intensive margin). ${ }^{4}$ Although we focus on the choice of checks for payment, our data allow us to take into account the key characteristics of a wide range of alternative payment instruments that influence consumers' simultaneous choices of checks and other payment instruments in a way that other studies have not. These data also enable us to estimate models of demand for each non-check payment method (debit cards, credit cards, ACH payments, and online bill payments). Extending the literature further, we estimate models of the change in payment use and of the substitution of electronic methods for checks. Our data come from a convenience sample of Federal Reserve employees in 2004, which were surveyed as part of a consumer payment research program at the Boston Fed (see Benton et al 2007). We also provide evidence from a nationally representative follow-up survey conducted by the AARP in 2006. Together, these data and econometric models provide one of the most comprehensive assessments of consumer payment choice to date.

A relatively novel feature of our econometric work is the investigation of the role of payment characteristics in consumer payment demand. Our data contain a rich set of variables

\footnotetext{
${ }^{3}$ For more details, see the Consumer Behavior and Payment Choice conferences sponsored by the Federal Reserve Bank of Boston in 2005 and 2006 (http://www.bos.frb.org/economic/eprg/conferences.htm).
} 
containing consumers' relative assessments of seven fundamental characteristics embodied in payment methods: cost, convenience (ease), safety, privacy, errors, timing, and record keeping. We assume that these characteristics yield utility to consumers, and thus represent an important determinant of the demand for payment methods, so we include them along with standard explanatory variables found in the literature (such as demographics and determinants of money demand). Although we are not the first to include payment characteristics, our data and modeling efforts are relatively extensive. Carow and Staten (1999) limited their sample to consumers with payment cards, Klee (2006b) lacked data on individual consumer demographics, and Borzekowski, Kiser and Ahmed (2007) included only a very limited set of payment characteristics in studying one payment method (debit cards). Jonker (2005) took a substantively different approach, modeling consumer payment choice using consumer attitudes and perceptions about payments, which are less objective and measurable than payment characteristics and pose even more serious econometric problems.

Our central finding is that payment characteristics are much more important for explaining the cross-section pattern of consumer payment demand than other standard variables used in previous studies. ${ }^{5}$ Payment adoption and payment use models that exclude payment characteristics generally explain less 10 percent of the cross-section variation in consumer payment demand, whereas the full models that include payment characteristics can explain 30 to 40 percent. Moreover, once payment characteristics are included, many standard variables become statistically insignificant or economically unimportant (or both). For example, age effects readily apparent in raw payment adoption data, such as the decline in adoption of online bill payment with age, diminish markedly after controlling for payment characteristics. A key factor driving the success of payment characteristics is that payment demand is far more heterogeneous within demographic groups than across them, and consumers' assessments of the payment characteristics explain a significant portion of this variation within groups.

However, the econometric results motivate further investigation of the meaning of payment characteristics and their role in consumer payment choice. Although consumers' reported characteristics are assumed to be valid summary statistics of the true characteristics embedded in the payment methods, errors in these variables may arise. Reported characteristics

\footnotetext{
${ }^{4}$ For examples, see Stavins (2001), Mester (2003), Hayashi and Klee (2003), and Zinman (2007).
} 
may reflect errors associated with limited information, measurement, and subjective perceptions; we explore instrumental variables techniques to try to correct for these problems. Regardless, variation in payment demand across consumers but within demographic groups appears to be driven largely by heterogeneity in payment characteristics across consumers, and this heterogeneity is reasonably well captured by the signal in consumers' assessment of characteristics.

The remainder of the paper is organized as follows. Section II presents an overview of the payments transformation for context and motivation. Section III contains an extensive review of the literature. Section IV describes the payment demand models and econometric specifications. Section V summarizes the consumer payment survey and data obtained from them. Section VI reports the econometric results. And Section VII concludes.

\section{The Payments Transformation}

Figure 1 plots the time series of check volume in the United States since 1970 using the best available data. The bars represent total U.S. check volume, and the line represents the volume of U.S. checks processed by the Federal Reserve only. After rising for approximately 25 years, total U.S. check volume finally began to decline from 50 billion in 1995 to 42 billion in 2000 (about 16 percent). ${ }^{6}$ However, because of a general lack of publicly available, highquality, high-frequency data on check volumes, this estimated decline in check volume was not revealed until 2002 and the exact timing of the underlying trend remains unclear (Gerdes and Walton 2002). Since this announcement, the Federal Reserve has stepped up its estimation of check volumes to every three years, reporting a further decline in check volume to 30.6 billion in 2006.

The core volume of checks processed by the Federal Reserve, which are high-quality data available quarterly since the early 1980s, continued to increase through the early 2000s before showing evidence of declining as well. ${ }^{7}$ These volume data, which account for less than half of

\footnotetext{
${ }^{5}$ Kim, Widdows and Yilmazer (2006) obtain qualitatively similar results for internet banking with a more limited set of payment characteristics.

${ }^{6}$ As a share of GDP, however, check volume has been declining steadily throughout this period. Thus, assuming no change in the average inflation-adjusted amount per check, the use of checks as payment method has been declining for much longer than the absolute volume of checks.

${ }^{7}$ This core processed volume excludes a small proportion of highly variable checks that were affected by special factors; for more details, see Benton et al (2007).
} 
total U.S. check volume, were readily available but apparently did not provide a representative picture of the aggregate trend in U.S. check volume.

Although checks remain the single most common form of non-cash retail payment, the long-awaited paper-to-electronics transformation is under way and electronic payments together now account for the majority of non-cash payments. According to the Federal Reserve System (2007), the share of checks dropped from 60 percent of all non-cash retail payment transactions in 2000 to 45 percent in 2003 and to 33 percent in 2006; thus, for the first time, the number of electronic retail payments exceeds the number of checks. To make more electronic payments, consumers are adopting alternative instruments, such as debit cards, bank account deductions via the Automatic Clearing House (ACH) network, and online bill payment, as shown in Figure 2. While the adoption of checks and credit cards (a traditional electronic payment instrument) remained flat from 1995 to 2004, consumer adoption of debit cards, ACH payments, and online bill payments jumped significantly.

\section{Literature Review}

Although the literature on the supply side of payments is fairly extensive, little research has been done on the demand side for payment methods. Data on individual consumer payment behavior are especially difficult to get. $^{8}$ Several papers analyzed the effects of individual consumers' socio-demographic characteristics on the adoption of payment methods (Stavins (2001), Bertaut and Haliassos (2005), Kim, Widdows and Yilmazer (2005), Klee (2006a), Zinman (2007)) or showed adoption rates by demographic cohort (Mester (2003, 2006), Anguelov, et al. (2004)). Those studies use the Survey of Consumer Finances data and find strong effects of demographic characteristics on the adoption of payments. Although the SCF contains a set of questions on consumers' adoption of payment methods, it has very limited information on the use of payments and on what affects consumers' payment behavior.

Amromin, Jankowski and Porter (2007) used data on actual consumer behavior and found that both income and education were significant in estimating adoption of the electronic tollway payment device in Illinois. A few researchers used proprietary data to explore consumer

\footnotetext{
${ }^{8}$ Some researchers estimate payment method use or adoption using country-level data. They include Amromin and Chakravorti (2007), Humphrey, Kim and Vale (2001), and Humphrey, Pulley and Vesala (1996). However, heterogeneity within each country can be substantial and one cannot infer what payment or consumer characteristics induce specific payment behavior based on aggregate international comparisons.
} 
payment behavior. Rysman (2007) used consumer transaction data from Visa’s Payment Systems Panel Study and found demographic attributes to be largely insignificant in predicting the choice of credit card network. Fusaro (2006) found age and income to be significant in debit card adoption using proprietary data on consumers' accounts held at a single small depository institution. In general, debit and online payment adoption and use were found to increase with age, while credit adoption tends to increase with income.

Demographic attributes were found to influence consumer payment behavior, but heterogeneity in payment behavior within demographic groups can be large (see Benton, Blair, Crowe and Schuh 2007) and substantial part of the variation in consumer payment use remains unexplained. Therefore including the characteristics of the payment methods and consumer perception of those methods could supplement or even replace the effect of demographics. A number of researchers used other sources of data to examine the effect of payment characteristics and consumer perceptions on payment behavior.

Anguelov, et al. (2004) showed that the use of electronic banking technologies varies with consumers’ perception of electronic banking. Kim, Widdows and Yilmazer (2005) showed that adoption of Internet banking is more likely among consumers who have good computer skills, are experienced with other banking technologies, or work in occupations related to the computer or Internet. Similarly, Hayashi and Klee (2003) found that consumers who used computers were more likely to adopt debit cards or electronic bill payments.

Carow and Staten (1999) estimated the effect of demographic characteristics and selected attributes of payment methods on consumers' choice of payment method at gasoline stations. Age, education, and income had significant effects on payment choice. Payment characteristics, namely convenience, record keeping and acceptance, were also found to have a positive effect on payment choice. However, their sample included cardholders only, and the questions were limited to cash, credit and debit use at gasoline stations.

Jonker (2005) used a survey of Dutch consumers and found consumers’ perceptions of payment methods to be important in payment use. Differences in those perceptions were more important than payment location in explaining differences in payment choice among the Dutch consumers. Jonker regressed consumers’ perceptions of payment methods, such as speed, cost and safety, on a set of socio-demographic variables. In most of the regressions, the estimated $\mathrm{R}^{2}$ 
was below 0.01, indicating that demographic characteristics do not explain differences in consumers' perception of payments.

Klee (2006b) examined what affected consumers’ choice between checks and debit cards at grocery stores. Speed and cost of transaction, record keeping, value and type of purchase were found to be significant. Although both transaction and payment method characteristics turned out to be significant in payment choice, the data had no demographic information on individual consumers, and therefore it is impossible to predict whether payment characteristics would remain significant when individual consumer demographic data were included in the estimation. Mantel (2000) explored the effect of consumer preferences on the adoption of electronic bill payment, using the results of a national survey. He found that consumer perceptions of control, record keeping, convenience and privacy affected consumers’ adoption of electronic bill payment.

In two of the very few papers that address the question why consumers use or do not use certain payment methods, Borzekowski and Kiser (2006) and Borzekowski, Kiser and Ahmed (2007) used a survey conducted as a special unit of the Michigan Survey of Consumers in 2004. They estimated debit card adoption and use as a function of socio-demographic characteristics of consumers, but also used open-ended responses to analyze the reasons why consumers choose to use or not to use debit cards. Convenience was the main reason to use debit cards, with cost, speed and restraint from spending mentioned as secondary reasons. Although they estimated consumers’ preferences with respect to a few characteristics of payment methods—-speed; electronic versus paper; and liquidity versus debt - the survey did not fully explore the attributes of various payment methods and thus did not allow for a complete analysis of consumer payment behavior.

Ching and Hayashi (2006) used the 2005 Dove Consulting/ABA survey data to estimate the effect of demographic attributes and consumers' perceptions of payment methods on payment adoption and use. When perceptions of payment methods were included in the regressions, the fit improved substantially and demographic attributes became less significant.

The empirical results in the literature show that both socio-demographic attributes and payment method characteristics affect consumer payment behavior. However, none of the papers cited above include a comprehensive set of payment methods or a broad set of payment 
method characteristics. The contribution of our paper is to include a wide range of payment characteristics in empirical estimation of payment method adoption and use.

\section{Models of Payment Demand}

This section describes the reduced-form models of payment demand and the econometric issues associated with them. The payment instruments modeled are: paper checks ( $C K$ ); credit cards ( $C C$ ); debit cards ( $D C$ ); automated clearing house ( $A C H$ ); online banking, or bill payment $(O B) .^{9}$ We estimate four types of empirical models - one payment adoption, and three types of payment use - for each available payment instrument.

\subsection{Adoption of Payment Instruments}

The first decision consumers make with regard to a payment instrument is whether or not to adopt it (the extensive margin). Adoption is defined as a discrete binary variable,

$$
A_{i j t} \equiv\left\{\begin{array}{cc}
1 & \text { if consumer } i \text { has adopted payment instrument } j \text { as of period } t \\
0 & \text { otherwise }
\end{array}\right.
$$

where $j=\{C C, D C, A C H, O B\}$. We do not estimate an adoption model for checks because virtually all respondents in the Boston Fed survey have adopted checks (adoption rate of 99 percent, Table 1). ${ }^{10}$ Empirically, respondents are classified as having adopted a payment instrument ("adopters") if they either: 1) checked "Yes” to the survey question, "Do you use it?"; or 2) entered a positive number for the survey question, "Number of payments."11 We estimated the econometric models of adoption with standard logit techniques.

\subsection{Use of Payment Instruments}

Once consumers adopt a payment instrument, their second decision to make is how often to use it to pay for their purchases (the intensive margin). Use is the absolute number of payments made by consumer $i$ using instrument $j$ during period $t$, or $n_{i j t}$, where

\footnotetext{
${ }^{9}$ Cash ( $C S$ ) is excluded because questions about it were omitted inadvertently from the Boston Fed the survey. In this draft, stored value cards ( $S V C$ ) also are excluded because their low rate of adoption significantly reduces the sample size of the common set of explanatory variables associated with payment characteristics.

${ }^{10}$ The essentially universal adoption of checks among Federal Reserve employees is a result of the System's human resources policy to require direct (electronic) deposit of wages and salaries.

${ }^{11}$ See Boston Fed consumer payment survey question 9.
} 
$j=\{C K, C C, D C, A C H, O B\}$. Empirically, use is measured by respondents' numeric answers to the survey question "Number of payments" during a "typical month" for each non-cash payment instrument. $^{12}$ We model relative use with the share of monthly payments,

$$
U_{i j t} \equiv\left(\frac{n_{i j t}}{N_{i t}}\right),
$$

where $N_{i t} \equiv \sum_{j} n_{i j t}$ is the total number of non-cash payments made by consumer $i$ in the month using all of the payment instruments. This measure of payment use assumes that the relative number of payments is reported accurately. ${ }^{13}$ Because it is a continuous (though bounded) variable, we estimated the econometric models of payment use with standard OLS techniques.

The longitudinal questions in the payment surveys offer data that permit the modeling of changes in payment use. One such model is the qualitative change in the use of each payment instrument. Change in use is defined as the discrete variable

$$
C U_{i j t} \equiv\left\{\begin{array}{cc}
1 & \text { if use increased } \\
0 & \text { if use was the same } \\
-1 & \text { if use decreased }
\end{array}\right.
$$

where $j=\{C K, C C, D C, A C H, O B\}$ and the change is measured over a particular period of time ending in period $t$. Empirically, change in use is measured by respondents' answers to the question, "Looking back over the past THREE years, for each payment method you use, indicate whether your use has increased, decreased, or stayed the same." ${ }^{14}$ We estimated the econometric models of change in payment use with ordered logit techniques.

Because the payment survey was designed to learn why the use of checks had declined, it included a question asking respondents directly why they switched from checks to other instruments. Thus, another informative model is the substitution of non-check payment instruments for the use of paper checks. Substitution of use is defined as the set of discrete binary variables

\footnotetext{
${ }^{12}$ See Boston Fed consumer payment survey question 9.

${ }^{13}$ If respondents have a systematic bias in their payment use reporting across instruments, such as undercounting due to memory loss, then the share of total payments may still provide an accurate estimate of relative payment use. ${ }^{14}$ See Boston Fed consumer payment survey questions 18. Note that the length of period of change is a difficult choice. Shorter time spans, such as one year or less, are susceptible to influence by unusual transitory events that might influence payment behavior, like unemployment. Much longer time spans are susceptible to influence by
} 


$$
S U_{i j t}=\left\{\begin{array}{lc}
1 & \text { if respondent substituted instrument } j \text { for checks } \\
0 & \text { otherwise }
\end{array}\right.
$$

where $j=\{C C, D C, A C H, O B\}$ and the substitution is measured over a particular period of time ending in period $t$. Empirically, the substitution of payment instruments for checks is measured by respondents' answers to a series of questions, “If you use [payment instrument $j$ ] for some purchases or bills you previously paid by check, what made you switch?"15 Each question offers multiple answers specific to the particular non-check instrument. Substitution from check to the alternative instrument is assumed to have occurred if the respondent checked at least one answer to the question. ${ }^{16}$ We estimated the econometric models of substitution for check use with standard logit techniques.

\subsection{Models of Payment Demand}

Following the literature on consumer payment choice, we specify reduced-form models of payment demand for each of the four measures of adoption and use. Denoting the vector of payment demand variables as $Y_{i j t}=\left\{A_{i j t}, U_{i j t}, C U_{i j t}, S U_{i j t}\right\}$, the econometric models can be written generically as

$$
Y_{i j t}=f\left(D E M_{i t}, M D_{i j t}, C H A R_{i j t}\right)+\varepsilon_{i j t},
$$

where $j$ varies for each payment choice variable as described earlier. The first vector of explanatory variables, $D E M_{i t}$ denotes demographic variables pertaining to respondent $i$ at time $t$. These variables, which are independent of the payment instruments, capture the effects of consumer lifecycles, experience, culture, or other socio-economic forces that influence payment choice. The second vector of explanatory variables, $M D_{i j t}$ denotes the standard determinants of money demand, such as income, wealth, and interest rates. These variables are the determinants of consumers' demand for money that may influence their choices of the payment instruments,

structural changes in payments or respondent memory deterioration. The three-year time span was chosen to balance these concerns and hopefully identify the trends currently driving respondent behavior.

${ }^{15}$ See Boston Fed consumer payment survey questions 19-22. Note that we cannot model the substitution of SVC payments for checks because the survey did not include a substitution question for SVCs.

${ }^{16}$ The data offer many more possibilities for understanding the substitution for checks, which we have not explored yet. For example, from these same questions, we know how many non-check payment instruments the respondent substituted for checks and the reasons why they made the substitution. Future drafts will explore these and other related issues. 
which are related to various components of money. Although income and wealth are determined simultaneously with payment choice, we view them as exogenous because the choice of payment instrument is unlikely to affect income or wealth. Interest rates, however, are more likely to be endogenous with the payment choice. Finally, the last vector of explanatory variables, $C H A R_{i j t}$, denotes the consumer-specific characteristics of each payment instrument.

In this version of the paper, we estimate all payment demand models independently (both across models and across payment instruments within models). For adoption, this decision may not be a bad approximation unless the likelihood of adoption is increasing in the number of instruments adopted, perhaps due to experience effects. For use, however, the assumption of independent models is problematic because the model dependent variable is the share of payments. Hence, an increase in the use (share) of one instrument necessarily requires a decrease in used of at least one other instrument. In future versions of the paper, we will employ system estimation techniques to account for these relationships.

\subsection{Demographics}

The vector of demographic variables from the Boston Fed survey (superscript B, to distinguish it from the AARP survey demographics) used in the econometric estimation includes age, education, and region categories:

$$
D E M_{i t}^{B} \equiv\left\{A G E_{i t}^{B}(6), E D U_{i t}^{B}(4), R E G_{i t}^{B}(12)\right\},
$$

where the value in parentheses indicates the number of categories. ${ }^{17}$ The age categories are:

$$
A G E_{i t}^{B}=\left\{\begin{array}{llllll}
<25 & 25-34 & 35-44 & 45-54 & 55-64 & \geq 65
\end{array}\right\} .
$$

The education categories are:

$$
E D U_{i t}^{B}=\{\text { High school or less Some college College Post-graduate }\} ;
$$

And the region categories are the 12 Federal Reserve Districts plus the Board of Governors. ${ }^{18}$

${ }^{17}$ The AARP survey (superscript A) offers a much richer vector of demographic variables that includes sex (or gender), age, marital status, household composition, household size, education, and race:

$$
D E M_{i t}^{A} \equiv\left\{S E X_{i t}^{A}(2), A G E_{i t}^{A}(60+), M S_{i t}^{A}(6), H H C_{i t}^{A}(4), H H N_{i t}^{A}, \operatorname{EDU}_{i t}^{A}(7), R A C E_{i t}^{A}(6)\right\} .
$$

However, the AARP survey data do not include payment characteristics for non-adopters and thus cannot be used to estimate the econometric models of payment demand.

18 The Districts are Boston, New York, Philadelphia, Cleveland, Richmond, Atlanta, Chicago, St. Louis, Minneapolis, Kansas City, Dallas, and San Francisco (see http://www.federalreserve.gov/otherfrb.htm). Although the Board of Governors is located geographically in the Richmond District, the Board is included separately to control for any potential location-specific effects in Fed employees. 


\subsection{Money Demand}

As discussed earlier in the literature review, most of the payment instruments are either components of money or at least indirectly related to the demand for money as transaction balances. We expect that the traditional determinants of the demand for money would also influence at least partly the consumer's demand for the payment instruments that are used to make transactions. Thus, the vector of money demand variables from the Boston Fed survey used in the econometric estimation includes income, wealth, and interest rate categories:

$$
M D_{i j t}^{B} \equiv\left\{\operatorname{INC}_{i t}^{B}(4), W E A L T H_{i t}^{B}(2), I N T_{i, C K, t}^{B}(2)\right\} .
$$

The income categories,

$$
I N C_{i t}^{B} \equiv\{<\$ 50,000 \quad \$ 50,000-74,999 \quad \$ 75,000-99,999 \geq \$ 100,000\},
$$

are measured in nominal (year-2004) dollars and are estimates of respondents' total household income. The wealth categories,

$$
W E A L T H_{i t}^{B} \equiv\{\text { Rent Own }\} \text {, }
$$

are a crude measure of assets determined by the respondents' home ownership status - home owners being presumed to have higher wealth than home renters. And the interest rate categories,

$$
I N T_{i, C K, t}^{B} \equiv\{\text { Yes } \quad \text { No }\}
$$

are based on the survey question, “Does your primary checking account earn interest?"19 This measure provides modest cross-section variation in the primary determinant of the consumerspecific velocity of money for at least one payment instrument. [NOTE: This variable is not included in the regressions in this version of the paper, but will be in future versions.]

In standard theoretical models of money demand, both money and its determinants (income, wealth, and interest rates) are viewed as being endogenously determined - a view with which we would agree. Therefore, one might argue for need to account for potential simultaneity bias in the payment demand models. Although we cannot rule out this possibility, we argue that while the total demand for payment instruments - that is, the total demand for money - by the consumer is endogenous, the actual composition of demand for payment instruments is not endogenous. In other words, the consumer's choice of the mix of payment

\footnotetext{
${ }^{19}$ See Boston Fed consumer payment survey question 3.
} 
instruments does not influence his income or wealth, at least to a first approximation. However, a stronger case for simultaneity might be made with regard to the interest rate.

\subsection{Payment Characteristics}

The vector of payment characteristics from the Boston Fed survey used in the econometric estimation includes cost (out of pocket), ease of use/convenience, safety from theft/misuse, privacy of personal identity, errors by banks/stores, payment timing/control, and payment record keeping:

$$
C H A R_{i j t}^{B} \equiv\left\{\operatorname{COST}_{i j t}^{B}, E A S E_{i j t}^{B}, S A F E_{i j t}^{B}, P R I V_{i j t}^{B}, E R R_{i j t}^{B}, T I M E_{i j t}^{B}, R E C_{i j t}^{B}\right\},
$$

where $j=\{C C, D C, A C H, O B, S V C\}$ and each characteristic for the non-check payment instruments is defined relative to the same characteristic for checks ( $C K$ ). For example, the cost of credit cards is defined relative to the cost of checks. Empirically, the consumer-specific payment characteristics for each instrument are measured by respondents' answers to the series of questions for each characteristic-instrument pair: “[Instrument $j$ ] versus checks: [Instrument $j$ ] is [better, same, worse] for [characteristic $k$ ]?" 20 These consumer-specific relative characteristic ratings define a set of qualitative characteristic variables as

$$
C H A R_{i, j_{-} C K, t}(k)=\left\{\begin{array}{cc}
1 & \text { if instrument } j \text { is better than check } \\
0 & \text { if instrument } j \text { is the same as check } \\
-1 & \text { if instrument } j \text { is worse than check }
\end{array}\right.
$$

for each of the seven payment characteristics (indexed by $k$ ) listed above. These relative (to check) characteristic ratings are reported directly in the respondents' answers to the survey. For regressions in which checks are the dependent variable, we multiply the characteristics relative to check by -1 to renormalize the variables so they are interpreted analogously to the characteristics in the other models.

In theory, all relative payment characteristics may be helpful in explaining payment instrument demand, analogously to relative prices in systems of consumption demand. For example, the cost of credit cards relative to debit cards may also be important like the cost of credit cards relative checks. Using the "reported” (or “observed”) characteristic ratings relative to checks, we can obtain "derived” estimates of all the remaining relative characteristic ratings

\footnotetext{
${ }^{20}$ See Boston Fed consumer payment survey questions 27-31.
} 
(except cash, which was not included in the survey). Assuming strict transitivity of characteristics, we define the relative characteristic of payment instruments $j$ and $j^{\prime} \neq j$ as the difference between their respective characteristics relative to checks,

$$
\mathrm{CHAR}_{i, j_{-} j^{\prime}, t}^{d}(k)=\mathrm{CHAR}_{i, j_{-} C K, t}(k)-\mathrm{CHAR}_{i, j^{\prime}-C K, t}(k),
$$

where the superscript $d$ distinguishes derived from reported characteristics. Given the range of the reported characteristics, $\mathrm{CHAR}_{i, j_{-} \mathrm{CK}, t}=[-1,1]$, the domain of the derived characteristics is $C H A R_{i, j_{-} j^{\prime}, t}^{d}=[-2,2]$. Figure 3 shows the nine possible outcomes for the derived characteristics, which include five unique integers.

Although the derived characteristics appear to have a richer information structure than the reported characteristics, this appearance is misleading. Reported characteristics are qualitative better, same, or worse - so there is not strict transitivity in their valuations across payment instruments. ${ }^{21}$ For example, if credit cards, debit cards, and ACH payments all are rated better in ease of use/convenience than checks, the characteristic ratings not reveal which one is the most convenient alternative to checks. For each of the three alternatives, the derived characteristics for ease would be zero (the lower right corner cell of Figure 3), suggesting that they are all equally convenient when they may not be. On the other hand, these derived characteristics would accurately reflect the fact the qualitative rating of each instrument's characteristic would be the same relative to checks. In contrast, the derived characteristics with values of -1 or 1 accurately reveal the difference in ratings relative to checks for any two alternative payments. But because there are two values of each, the derived characteristics do not reflect the underlying rankings relative to check of the two alternatives unequivocally (they could be better and same, or same and worse). Only the extreme derived characteristics values of -2 and 2 provide an unequivocally clear signal of the underlying characteristics relative to checks. For all of these reasons, we expect the reported characteristics to be more significant and reliable than the derived characteristics in the econometric models, but the accuracy of the extreme derived characteristic values may be useful in explaining outlier payment decisions.

Although a deep theory of payment characteristics does not exist (to our knowledge), we assume the characteristic yield a flow of utility to the consumer when a payment method is used. This assumption rests the logic of the standard money-in-utility model, $U_{i t}=U\left(C_{i t}, M_{i t}\right)$, in 
which consumption ( $C$ ) and money balances ( $M$ ) yield utility. The additional assumption we make is that money depends on the payment characteristics, $M_{i t}=M\left(C H A R_{i j t}\right)$. Consumers choose an optimal utility-yield of payment characteristics by choosing payment methods appropriately, so the payment characteristics are potentially endogenous. A formal system of payment demand functions can be derived in the usual way.

\subsection{Econometric Issues with Characteristics}

In theory, the use of utility-yielding characteristics to explain the demand for payment instruments in reduced-form models is sound provided the characteristics are tangible, objective, measurable, and exogenous (or pre-determined). In practice, the reported characteristics may suffer difficulties in one or more of these dimensions. This section discusses these potential difficulties and possible solutions to them.

In principle, all of the payment characteristics are tangible and objective to an extent. Cost (essentially a price), the timing/control of the payment with regard to deduction from a bank account, and the frequency of transaction errors are probably the most tangible and objective characteristics. At the other end of the spectrum is "convenience (ease of use)," a term that is used widely but universally decried as imprecise. Some aspects of payment instrument convenience may be tangible and objective - such as speed, physical dimensions, and acceptability - but these are jumbled together in this catchall characteristic. Moreover, it is easy to imagine subjective perceptions of convenience by consumers. Safety and privacy protection are related to the probabilities of theft and the losses of money and information associated with that theft. Record keeping reflects the form and availability of information about payments.

Given that the characteristics are tangible and objective in principle, they can also be measured empirically, but this task is difficult even for the most easily measured characteristics. Perhaps the best example is the cost (or price) of payment instruments, but even here there are measurement issues. [INSERT brief discussion of the Hahn et al and other related papers here]. Likewise, the definition and measurement of "identity theft," which encompasses safety and privacy protection, has been elusive. [INSERT brief discussion of ID theft literature here - see Schreft's new paper]

${ }^{21}$ However, the relative characteristic variable definition at least does not allow for false preference reversals. 
These issues can be specified in terms of a linear (for simplicity) errors-in-variables framework. Thus, the reported characteristics are

$$
C H A R_{i j t}=C_{i j t}^{*}+\eta_{i j t},
$$

where $C_{i j t}^{*}$ represents the "true" consumer-specific characteristic for payment instrument $j$, and $\eta_{i j t}$ is the error or deviation from the true value. Regarding $C_{i j t}^{*}$, two points are crucial. First, some part of each characteristic must be true - that is, tangible, objective, and measurable - in a meaningful sense, at least in theory. As discussed previously, we believe this to be the case. In practice, however, all we need for the characteristics to be valid empirically is that consumers' reported characteristics be positively correlated with the true value. Second, we allow the true characteristics to vary across consumers within payment methods. For example, two consumers can have different assessments of the cost of a credit card relative to a check because of factual differences in their idiosyncratic choices of the fees, interest rates, and rewards associated with these payment methods. However, because each of these cost factors is chosen endogenously by the consumer in some sense, regressions with contemporaneous values of the characteristics may be subject to simultaneity bias.

Furthermore, the characteristic error likely contains at least three components,

$$
\eta_{i j t}=\eta_{i j t}^{I}+\eta_{i j t}^{M}+\eta_{i j t}^{P},
$$

associated with limited information (superscript $I$ ), classic measurement error (superscript $M$ ) and subjective perceptions (superscript $P$ ). Limited-information errors may arise because the consumer's information set, $\Omega_{i t} \in \Omega_{t}$, is a subset of all aggregate information available. For example, a consumer may not know all the fees charged for a payment card or may only be marginally aware of the actual risks of identity theft. Classic measurement errors may arise simply because data collected on the characteristics may be biased or noisy, for example. And subjective perception errors may arise from behavioral effects of decision making, irrational fears, advertising, or other psychological and emotional factors. Of course, subjective perception errors are not well handled in classical econometrics, so we merely point them out as a potential area for future (perhaps interdisciplinary) research.

One possible to solution to both the simultaneity bias and errors-in-variables problems is to use instrumental variables estimation, which we explore and report in the results section. In addition to the usual challenge of finding relevant and exogenous instruments, we do not have 
many choices of valid instruments to choose from our consumer-level data sources. Because the demographic variables do not turn out to be very significant explanatory variables in the presence of the characteristics, a logical set of instrument candidates is $D E M_{i t}$. We report selected results of first-stage IV regressions,

$$
C H A R_{i j t}^{B}=g\left(D E M_{i t}^{B}, Z_{i j t}^{B}\right)+v_{i j t}^{B},
$$

where $Z_{i j t}^{B}$ is a set of miscellaneous, potentially payment-method-specific instruments. These regressions indicate the potential relevance of the demographics as instruments and may reveal potentially valuable socio-economic interpretations of the payment characteristics. Note that Jonker (2005) runs regressions like these her the consumer perceptions of payments in her data and treats the regressions as behavioral. Instead, we argue that the true characteristics are endogenous and need to be handled as such.

\section{Consumer Payments Data}

Our data come from two versions of a consumer payment survey that is part of an ongoing research program initiated by the Federal Reserve Bank of Boston in 2003. The data used in our regression analysis come from a survey conducted with a convenience sample of Federal Reserve System employees in 2004, and the data used in our empirical analysis come from a subsequent survey conducted by the AARP with a sample intended to represent all U.S. consumers in 2006. ${ }^{22}$ Henceforth, we refer to these data as "Fed” and “AARP.” Although each survey has some flaws and limitations, the data provide unique and relatively reliable information about consumer payment choices. For more details about the 2004 Fed survey and the Boston Fed research program, see Benton, Blair, Crowe, and Schuh (2007).

\subsection{General Survey Design}

The Boston Fed consumer payment survey program, motivated by the market paper-toelectronics transformation, is designed to gain a better understanding of the determinants of the demand by U.S. consumers for the main payment methods of today. The Fed and AARP surveys contain the following common elements:

\footnotetext{
${ }^{22}$ The original version of the survey was conducted with more than 500 employees of the Federal Reserve Bank of Boston (40 percent response rate) in 2003 as part of a leadership development program. A new version, with major
} 
- Adoption and use - The central part of the surveys elicits information about whether respondents' have the payment methods (adoption) and how often respondents use them. Questions are also asked about the following aspects of payment use:

o Change in the use of payments over the past three years

o The substitution of non-check methods for checks

o The types of payment use by location (retail shopping versus the internet), by types of bill payments, and by dollar amounts, for examples.

- Reasons for payment behavior - The surveys ask direct questions about the respondents' adoption and use decisions. These include:

o Why they have not adopted payment methods (called "barriers")

0 What changes would lead them to change their adoption and use

o How they responded to particular payment choices and why

- Respondent assessments of their payment characteristics - The surveys elicit information about how respondents rate the fundamental characteristics of payment methods.

- Respondent characteristics - The surveys contain questions about the characteristics of their respondents, such as demographics, income and wealth, financial sophistication and experience, and other relevant factors.

- Miscellaneous payment attitudes and experiences - The remainder of the surveys include various questions about respondents views about payment methods and what their experiences have been (or have not been) when using them especially particular aspects of checks such as conversion of checks to electronic forms by banks, stores, and billers.

The Fed and AARP surveys also have some modest general differences. By and large, the Fed survey is more heavily oriented to understanding the specifics of check behavior because of its business concern about the effects of the decline in check use. The AARP survey has more extensive information about respondent characteristics and reflects a number of methodological improvements over the Fed survey (in addition to it broader focus on all U.S. consumers). For reasons explained below, only the Fed survey data can be used to run regressions.

revisions and improvements, is being conducted jointly by the Boston Fed and the RAND Corp. in 2008 and 2009 with U.S. consumers as part of the American Life Panel. 


\subsection{The Fed Survey}

The Boston Fed conducted a 55-question version of the consumer payment survey with employees of the Federal Reserve System in June and July of 2004. ${ }^{23}$ The voluntary survey was administered on the Federal Reserve's intranet and made available to all locations in the System (twelve Reserve Banks and their branches plus the Board of Governors). Paper copies of the survey were also available, but only X percent of respondents chose paper. More than 5,300 employees responded for a response rate of 24 percent, which is quite favorable for payment surveys of this type. ${ }^{24}$ Only 4,631 observations are usable because of technical difficulties during one week of the survey. The primary advantages of the Fed survey are: 1) it queries the same respondents about a wide range of payment methods; 2) it asks respondents questions about both actions and attitudes; and 3) it probes the reasoning behind payment decisions by asking "why?"

The convenience sample of Federal Reserve employees has three unique potential drawbacks relative to other related surveys. First, Fed employees are older, richer, and more educated than U.S. consumers, on average. ${ }^{25}$ Moreover, the sample of employees in a professional workplace yields very few respondents aged 18-25 years or older than 65 years. For these reasons, aggregate statistics may not be accurate indicators of total U.S. payments behavior. Second, Fed employees likely are more highly educated about, and experienced with, payments than U.S. consumers. Third, Fed employees have had difficulty answering the survey questions exclusively from the perspective of a consumer who uses payments rather than Fed employee who provides payment services. ${ }^{26}$ For these latter two reasons, the Fed data may reflect sample selection effects related to the payments and financial sophistication of its respondents. ${ }^{27}$ These selection effects do not invalidate the differences observed in payments demand across the respondents. However, they should be kept in mind when interpreting the

\footnotetext{
${ }^{23}$ The Fed survey instrument and complete results (numeric and graphical) are available from the Boston Fed's Emerging Payment Research Group web site at http://www.bos.frb.org/economic/eprg/resources.htm.

${ }^{24}$ The response rate across Districts varied from 51 percent in Minneapolis to 12 percent at the Board of Governors. Response rates for other similar consumer payment surveys are ... [TO BE COMPLETED].

${ }^{25}$ The sample of Fed respondents is representative of all Fed employees, at least in terms of age.

${ }^{26}$ It is difficult to identify this effect for certain, but it is a concern. Some comments in the essay portions of the survey reflect the job-security concerns of check-processing employees, and some employees are directly involved in providing other payment services to banks and businesses (such as ACH, check imaging and conversion, etc.).

${ }^{27}$ In addition, like all other surveys of this nature, the Fed survey may suffer from general selection effects associated with respondents' willingness to take voluntary, time-consuming surveys.
} 
regression results because the determinants of payment demand for consumers with sophisticated payments practices may differ from those of U.S. consumers overall.

\subsection{AARP Survey}

The AARP conducted a 69-question revised version of the Fed consumer payment survey with U.S. consumers in the spring of $2006 .^{28}$ The voluntary telephone survey was administered by an outside vendor using standard list-assisted Random Digit Dialing (RDD), or Weighted (Type B) RDD, which screens out business and other non-household telephone numbers. The sample size was 1,500. Sample weights for four demographic characteristics (race, education, age-gender jointly) are applied to the data to make the survey responses consistent with U.S. Census population statistics. A representative sample is the primary advantage of the AARP survey over the Fed survey. However, the AARP survey excludes respondents under age 25 and only includes respondents who have most of the financial responsibility in their household (or share most of the responsibility with another household member), two restrictions not made in the Fed survey. Other important advantages of the AARP survey are that it included questions about cash, which were omitted inadvertently from the Fed survey, and it corrected some of the methodological problems in the Fed survey.

\subsection{Payment Characteristics Data}

The key explanatory variables - respondent ratings of payment characteristics - were adversely affected by a design flaw in the Fed and AARP surveys. In both cases, only respondents who had adopted the payment method (“adopters”) were asked to rate the payment characteristics. $^{29}$ Thus, in principle, the characteristics cannot be used as explanatory variables for regressions models of payment adoption because there is no variation in the dependent variable for ( $A_{i j t}=1$ for all respondents with non-missing characteristics data). A similar problem exists for models of payment use, although it is less severe because use (payment share) varies across individuals who have adopted the payment method.

\footnotetext{
${ }^{28}$ The AARP survey instrument and complete results (numeric and graphical) will eventually be available from the Boston Fed's Emerging Payment Research Group web site at http://www.bos.frb.org/economic/eprg/resources.htm. ${ }^{29}$ The original rationale for this survey design choice was that non-adopters are unlikely to be familiar enough with a payment method to provide meaningful and accurate ratings of the characteristics embodied in it. Nevertheless, it is likely that even non-adopters have some assessments of the payment characteristics, and those assessments probably influence their payment choice - or non-choice, as the case may be - so the survey should asks all respondents to answer the characteristics questions. This problem is rectified in the 2008-09 RAND surveys.
} 
In practice, however, the Fed data can be used for regression analysis. Whereas the AARP survey mechanically prevented non-adopters from answering the characteristic questions, the Fed survey did not prevent non-adopters from answering the characteristics questions. In fact, a significant number of Fed respondents did not follow the directions so at least some nonadopters answered each characteristic question, providing enough data to run the payment demand regressions.

Although it is feasible to estimate the models, it may not be advisable if there are serious sample selection problems. About 40 percent of respondents who had not adopted a credit card answered the characteristics questions for credit card (even though the survey instructed them not to), and 12 to 15 percent of respondents who had not adopted the remaining non-cash, noncheck instruments answered the respective characteristics questions inappropriately. The main concern is not how many non-adopters answered the characteristics questions, but whether the non-adopters who answered inappropriately are systematically different from the non-adopters who followed directions and did not answer (in other words, selection bias).

Fortunately, we found little evidence of systematic differences in the observable traits of the two types of non-adopters. ${ }^{30}$ Of course, there may be some unobservable trait in nonadopters who don't follow directions that may be correlated with payment choice. But if not, the only apparent shortcoming of using the Fed characteristics data for the regressions is a potential loss of efficiency (standard errors) resulting from using only a subset of non-adopters.

\subsection{Adoption and Use}

Tables 1 and 2, and Figure 4 will be discussed here.

\section{Econometric Results}

This section describes regression results for the four econometric models: (1) adoption; (2) use; (3) change in use; and (4) substitution of electronic payments for checks. Coefficient estimates appear in Tables 3-6, with the shaded regions highlighting the reported characteristics (to distinguish them from the derived characteristics). Estimates of the use models are OLS coefficients on the share of payments; multiplied by 100, they represents the marginal effects of

\footnotetext{
${ }^{30}$ We compared the two types of non-adopters in terms of demographics, determinants of money demand, and payment adoption and use behavior but did not find economically large differences in these traits across the two
} 
the explanatory variables on the payment shares in percentage points. Estimates of the remaining models are odds ratios, which have an expected value of 1.0 when the explanatory variable has no economically significant effect on the dependent variable. Odds ratios greater than 1.0 reflect the marginal effects of the explanatory variables on the dependent variables in relative terms. For example, a ratio of 1.50 indicates that the explanatory variable yields a 50 percent greater chance of the dependent variable being in the next higher category; ratios less than 1.0 are interpreted inversely.

The demographic and money demand variables are converted to binary dummy variables and included separately. One category for each type of explanatory variable is omitted from the regression and the corresponding line left blank in the table. This control group represents the baseline for discussion of the relative results for all other variables of this type. The Federal Reserve District variables are included in the regressions but most are statistically insignificant so their estimates are suppressed from the tables.

\subsection{Sample Sizes}

The regression samples were chosen to maximize the comparability of the econometric results across payment demand models and payment instruments. To obtain roughly equivalent samples across payment instruments, we selected only respondents who answered all payment characteristics questions for each of the payment instruments that we model so there are no missing variables among the derived characteristics. This criterion produces 1,162 potentially usable observations for the regressions. ${ }^{31}$ Each regression model has a modest amount of idiosyncratic variation around this base sample. ${ }^{32}$

groups of non-adopters. A complete set of tables comparing the two groups will be available from the authors on request.

31 This strategy of estimating comparable models significantly reduces the available sample size. An alternative strategy would be to estimate models with only the reported characteristics, which are more significant and less susceptible to measurement error than the derived characteristics. Doing so would increase the sample sizes roughly threefold or more. We plan to explore this option for future versions of the paper.

32 The adoption sample $(1,159-1,162)$ varies because respondents over 65 are dropped in some cases due to lack of variation. The use sample (951-1,131) varies because respondents are required to be an adopter of the payment instrument. The sample for change in use $(1,045-1,112)$ varies due to missing observations on $C U_{i j t}$. The sample size for substitution of use $(1,162-1,163)$ varies because one more person answered the question about credit cards (question 19) than for the other three instruments. The latter two models did not require respondents to be adopters of the payment instrument because they may have adopted the instrument previously and then gotten rid of it. 


\subsection{Payment Adoption Models}

\subsubsection{General Results}

Table 3 reports results for the models of payment adoption for the four electronic alternatives to checks. ${ }^{33}$ Very few demographic or money demand variables are statistically significant. The particular variables that are significant differ across payment instruments, so these variables do not offer very consistent and reliable explanations for adoption of electronic payment instruments from these variables.

In contrast, many reported characteristics are statistically and economically significant. They also tell a consistent story: ease of use and payment timing are the primary determinants of electronic payment adoption. In almost every instance, respondents who reported that ease of use (convenience) and payment timing are better for the electronic payment instruments than for checks were much more likely to adopt the electronic alternatives - typically twice as likely, or even much more. Respondents who consider electronic payments to be better than check for payment timing probably appreciate the ability of electronic payments to avoid the delay and uncertainty arising from check float. Cost and safety also influence the adoption of some payment instruments, but these characteristics are not as important. Derived characteristics are important for adoption too, but they are less statistically and economically significant than the reported characteristics, and do not provide as consistent a picture of the determinants of adoption.

\subsubsection{Specific Results}

The adoption of credit cards appears to be rising in age and education, but only the relatively young (ages 25-34, less likely) and the highest education cohorts (post-graduate, more likely) have statistically significant coefficients. Respondents who rate the cost and timing of credit cards better than for checks (reported), and who rate ease of use and timing of credit cards better than for debit cards (derived), were about twice as likely to adopt credit cards. These respondents likely have credit cards with rewards and like the buy-now-pay-later option that credit cards offer. It is unclear how credit cards might be easier to use than debit cards.

The adoption of debit cards does not appear to be influenced by demographic or money demand variables; no coefficients are statistically significant. However, many characteristics do influence adoption. Respondents who rate the ease, safety, and timing of debit cards better than 
for checks (reported) are two to four times more likely to have adopted a debit card.

Respondents who rate the cost and record keeping of debit cards better than for credit cards or ease of debit cards relative to ACH (derived), are also more likely to have adopted a debit card. The latter result is surprising because debit transactions typically do not generate better records than credit transactions. Interestingly, the cost of debit cards relative to credit is a significant determinant of debit card adoption, but not the other way round. For some reason, respondents who rate the ease and timing of debit cards better than online banking are actually less likely adopt a debit card.

The adoption of ACH payments appears to be declining in age and rising in education, income, and wealth, but only the oldest (age 65 and over) and poorest (income $<\$ 50,000$ ) cohorts have statistically significant coefficients. Respondents who rate the ease and timing of $\mathrm{ACH}$ better than for checks (reported) are much more likely to adopt ACH payments. Ease of use for ACH over checks had a particularly strong effect, suggesting that the many people have set up ACH payments specifically to reduce check use and make their payment decisions much easier. The timing of ACH relative to checks likely stems from the elimination of uncertainty about float, mail delivery, and other related factors. Respondents who rate the record keeping of $\mathrm{ACH}$ better than for credit cards are also more likely to have adopted $\mathrm{ACH}$, although it is unclear how ACH records dominate credit card records. However, ACH was less likely to be adopted by people who think credit cards allow them to control payment timing of payments better, presumably because, unlike ACH, credit card transactions do not typically require the payment date to be determined in advance.

Like ACH, the adoption of online bill payments also appears to be declining in age and rising in education, income, and wealth, but only the second oldest (age 55-64) and poorest (income $<\$ 50,000$ ) cohorts have statistically significant coefficients. Respondents who rate the timing of credit cards better than for online bill payments, and ease of debit cards better than for online bill payments, are less likely to adopt online bill payments. These two intuitively sensible results are the only statistically significant coefficients for this model.

\subsection{Payment Use Models}

\subsubsection{General Results}

${ }^{33}$ No model for checks is estimated because the adoption rate for checks in the Fed survey is 99 percent. 
Table 4 reports results for the five models of payment use, including checks. Demographic attributes are somewhat more significant determinants, statistically and economically, of payment use than of the likelihood of payment adoption (compare Tables 3 and 4). The largest economic effects are associated with age and education. Income and wealth generally have no significant effect on the use of any payment instrument, perhaps because use is defined as the share of payments while income and wealth are levels.

Many of the reported payment characteristics are very statistically and economically significant determinants of payment use, as they are with adoption. But the story they tell is slightly different: ease of use and payment record keeping (rather than timing) are the primary determinants of payment use. Respondents who rate a payment instrument easier to use than checks are likely to have a monthly share of checks use that is several percentage points lower for checks (and higher for alternatives to checks). Given that ease of use is least precise type of characteristic, this result is rather unsatisfying. Respondents who rate a payment instrument better for record keeping are likely to have higher shares for those instruments too. Although record keeping is more objective and measurable than ease of use, it is hard to understand the source of heterogeneity in consumer assessments of the record-keeping feature of paper checks. Derived payment characteristics are quite important for credit and debit cards, but much less so for other instruments.

\subsubsection{Check Use}

Check use appears to be rising in age and declining in education. Consistent with previous findings, younger consumers (less than age 35) write fewer checks, their monthly shares being 4 to 7 percentage points lower and very statistically significant. Consumers with the highest education level (post-graduate degree) also have monthly check shares significantly lower by about 4 percentage points.

Ease of use is the most important payment characteristic affecting check use. In each of the four cases, respondents who rate checks easier (harder) to use than the electronic alternatives method were likely to have a 3 to 5 percentage point higher (lower) share of check payments each month - a very statistically significant result. Although it is puzzling and perhaps even surprising that respondents would disagree so widely about the ease of use of checks versus electronic payments - particularly at the retail checkout counter - this characteristic appears to consistently influence consumer preferences strongly enough to affect payment choice. 
Record keeping, cost, and safety (each measured relative to certain alternative instruments) also influence the use of checks. Respondents who rate checks better for record keeping than debit cards and online banking are likely to have a 2 to 4 percentage point higher share of checks. Check registers, which allow users to easily record payments and keep running account balances, and the availability of canceled checks could explain the importance of check records relative to debit card records for some consumers. Online banking records might be viewed as inferior for consumers who have difficulty accessing computers or whose bank does not retain easy and complete historical access to checks. Respondents who rate checks cheaper than debit cards or online banking are likely to have a 2 to 3 percentage point higher share of checks. These respondents may be more likely to be paying monthly or per-use fees for their debit card and online banking services. Finally, respondents who rate checks as being safer than online banking are likely to have a 3 percentage point higher share of checks. Anecdotes about consumer fears of identity theft may explain this result (but note that respondents appear to be concerned with safety but not loss of privacy).

\subsubsection{Electronic Payment Use}

Use of credit and debit cards appears to be declining in age and use of ACH and online banking appears to be rising in age. Younger consumers (less than age 35) have a 5 to 8 percentage point higher shares of credit and debit card use, but 2 to 5 percentage point lower shares of ACH and online banking use. When contrasted with the adoption results, these age effects tend to suggest and oddly opposite picture of payment behavior among the young. Younger consumers are less likely to have payment cards but use them more, and more likely to have adopted ACH and online banking but use them less. Respondents who are most highly educated (post-graduate degree) have a 4 percentage point higher credit card share. This result appears to be related to the lower use of checks by this demographic group, perhaps because they have become savvy at using rewards-based cards without revolving debt.

The reported characteristics relative to checks have a similar but less consistent impact on electronic payment use as they do on check use. Respondents who rated electronic payments better than checks in keeping records had a 1 to 3 percentage point higher share of all electronic payments (only the debit card coefficient was not significant). This result is a smaller but analogous result to that for check use. Debit cards are often viewed as more convenient than checks, so it is not surprising that respondents who consider debit cards easier to use than checks 
are likely to have an 8 percentage point higher share of debit payments. Similarly, respondents who rate debit card cheaper than checks are likely have a 3 percentage point higher share, but those who rate debit cards worse than checks on payment timing are likely to have a 3 percentage point lower share. In general, however, ease of use does not play the same strong and consistent role in determining the use of electronic payments as it does is the use of checks.

Among the derived payment characteristics, three features are important for determining the tradeoff between credit card and debit card use. Respondents who rate one type card better on cost, timing, and record keeping relative to the other type of card are likely to have a 2 to 5 percentage point higher share of payments with the card that has their preferred features. In fact, the coefficient estimates on these derived payment characteristics are nearly mirror images of each other (as they should be). Once again, understanding the sources of heterogeneity in these payment characteristics across consumers is crucial. Most likely, the fee structure of consumers' payment cards - including the benefits (negative cost) of payment card rewards such as frequent flyer miles - and interest costs (paid or earned on accounts) help explain variation in cost. But variation in ratings of timing and record keeping for the two cards is less clear.

\subsection{Change in Use}

In this set of regressions, we estimate the probability that respondents changed their use of each payment method during the previous three years. The dependent variable takes one of three possible values: decreased, stayed the same, or increased. We estimate the regressions using ordered logit, where a coefficient greater than 1 indicates that a respondent increased his use of the payment method (Table 5).

Demographic characteristics were largely insignificant, with the exception of the youngest cohort (under 25), for whom the use of all payments (except for debit) increased significantly, most likely because they started paying bills and increased their purchases during that period. Those in the lowest income group (below $\$ 50,000$ a year) decreased their use of debit.

Although the use of checks declined overall, ${ }^{34}$ consumers who increased their use of checks considered checks to be easier or lower-cost as compared to electronic payments. Ease of use of checks relative to online banking was especially important, and cost of checks relative to 
debit or ACH. Surprisingly, consumers who considered credit cards to be more costly than checks did not increase their use of checks significantly.

The use of all electronic payments increased for respondents who considered those payments to be better than checks when it comes to ease of use, timing of payment, and, to a lesser degree, record keeping. Ease of use of electronic payments relative to check, especially for online banking, was the most important characteristic affecting consumers' decision to increase their use of electronic payments. That result is consistent with our findings in the preceding regressions - even though the ease of use of electronic payments relative to checks is not universal, and some respondents still think that checks are easier, that characteristic is extremely important in affecting consumer payment use.

As we found in previous regressions, the relative cost of credit and debit was influential in affecting the change in use. Consumers whose cost of credit is lower than that of debit increased their use of credit, most likely due to rewards and float, while those whose cost of debit is lower than that of credit increased their use of debit, possible to avoid interest and fees.

\subsection{Substitution of Electronic Payments for Checks}

Demographic attributes did not affect the likelihood of substitution of electronic payments for checks (Table 6). So even though younger people use debit cards more often, we cannot conclude that they switched from checks to debit. Rather, it seems that younger consumers never used checks to the extent that older consumers did. The decision whether or not to substitute electronic payments for checks is affected by people's views of the payment characteristics, not by their socio-demographic characteristics.

Timing is the most important payment characteristic affecting the probability of substitution to any electronic payment from checks. Because of check float (both mail and processing), consumers who value having control over the timing of payment are likely to substitute for checks. Cost of credit cards relative to checks affected the likelihood of switching to credit cards, most likely because of the rewards that credit cards offer. As in the share regressions, ease of use is important when consumers substitute away from checks. Those who believe that $\mathrm{ACH}$ or online banking are easier to use than checks were likely to substitute those methods for payments previously paid by check. Clearly, being able to set up payments

\footnotetext{
${ }^{34}$ The decrease in check use came only from the intensive margin, and not the extensive margin (the fraction of
} 
electronically and not having to remember to pay bills is important for payment behavior. In the case of online banking, timing, ease of use, safety and cost were all significant in the decision to substitute for checks.

As in the adoption and share regressions, cost of debit relative to credit was significant. Consumers whose cost of debit is lower were more likely to substitute debit for check. Those who consider debit to be superior to credit for record keeping or privacy were also more likely to switch from check to debit. Those results are consistent with the high rate of growth of debit during the past several years, when the use of credit increased at a much lower rate.

\subsection{Model Evaluation}

When we estimate the regressions with just the socio-demographic attributes-age, education, homeownership and income — several of them appear to be important in explaining consumer payment behavior. However, when payment characteristics are included in the regressions, many of the demographic variables lose their statistical significance. That is because demographics may pick up some of the effects that should be attributed to consumers' assessment of payment characteristics.

For example, consumers in the lowest income group or those with less than complete college education were less likely to adopt credit cards, but the effect disappeared when characteristics were taken into account. In the case of ACH adoption, low levels of education and wealth (as measured by homeownership) were associated with lower rates of adoption, but both became insignificant in the full model estimation. Age seemed important in explaining the adoption of online banking with just the demographic attributes in the model, but not in the full model.

Table 7 compares adoption and use models with and without characteristics. The top panel of the table shows the fit (as measured by pseudo $\mathrm{R}^{2}$ ) of full model compared to restricted models: with reported characteristics only, with derived characteristics only, and finally with demographics and money demand variables only. In all cases the full model performs much better than any of the restricted models. We tested whether characteristics can be omitted from the regressions. As the bottom panel of Table 7 indicates, while excluding demographics could not be rejected in some cases, excluding characteristics was strongly rejected in every regression. 
Those results clearly indicate that even though payment use varies across the demographic cohorts to some extent, something else other than demographics affects consumer payment behavior, and demographic attributes likely pick up effects that are not captured in most empirical studies. This paper is the first attempt to systematically measure consumers' views of characteristics of all payment methods, and to test their influence on payment adoption and use.

\section{Conclusions}

Although it is now known that the number of paper checks written in the United States is falling, there still exists very little understanding of exactly why check volume is declining, who chooses what payment method and why. Moreover, many consumers have not reduced their check writing much at all, which is puzzling given the cost and convenience advantages of alternative payment methods.

This paper makes strides towards explaining consumer payment behavior by estimating empirical models of payment adoption and use. We focus on the recent transformation of the payment system from paper check to electronic payments to ask why some consumers use electronic payments and others continue to prefer checks. Previous literature has focused mainly on explaining payment behavior with socio-demographic attributes. We find that even though payment use varies across the demographic cohorts, variation within the cohorts is much greater and can be better explained by differences in payment characteristics across consumers, even when controlling for the demographic diversity.

We use data from a survey of Federal Reserve System employees conducted in June 2004 and specially designed to learn why consumers choose checks versus other payment methods and why they change their payment behavior. In the survey, respondents were asked to evaluate each electronic payment method along several attributes, relative to paper checks. We provide evidence that the fundamental characteristics of payment methods - cost, convenience, security, and the like - are much more important determinants of payment choice than traditional demographic and other observable variables. Payment characteristics increase the cross-section explanatory power of payment adoption and use regressions from less than 10 percent to more than 30 percent. Our findings show that the payment characteristics are important in explaining all four of the models reported here-payment adoption, use, change in use of individual payment methods, and substitution from checks to electronic payments. 
Predicting future changes in payment use is of vast importance to the Federal Reserve and to the financial services industry, because of resource allocation decisions associated with the infrastructure needed to process payments. The econometric results reported here show the importance of payment characteristics in explaining consumer payment choice. To understand and predict changes in consumer payment use, good measures of these characteristics are necessary. Moreover, we find that the relevance of individual characteristics varies across the models and across payment methods_convenience might affect some payment decisions, but control over timing might be the most important characteristic in other cases. It is crucial, therefore, to carefully measure all the relevant attributes. Although reported characteristics are assumed to be valid summary statistics of the true underlying characteristics, errors in these variables may arise due to limited information, measurement errors, and subjective perceptions. Future research should explore instrumental variables techniques to try to correct for these problems. 


\section{References}

Anguelov, Christoslav E., Marianne A. Hilgert, and Jeanne M. Hogarth. 2004. "U.S. Consumers and Electronic Banking, 1995-2003.” Board of Governors of the Federal Reserve System, Federal Reserve Bulletin, Winter, pp. 1-18.

Amromin, Gene, Jankowski, Carrie and Porter, Richard D. 2007. "Transforming Payment Choices by Doubling Fees on the Illinois Tollway.” Economic Perspectives, Vol. XXXI, No. 2, Second Quarter.

Amromin, Eugene and Sujit Chakravorti. 2007. Debit card and cash usage: a cross-country analysis. Federal Reserve Bank of Chicago. Working Papers WP-07-04, March.

Benton, Marques, Krista Blair, Marianne Crowe, and Scott Schuh. 2007. "The Boston Fed Study of Consumer Behavior and Payment Choice: A Survey of Federal Reserve System Employees.” FRB Boston Public Policy Discussion Paper no. 07-1.

Bertaut Carol C. and Michael Haliassos. 2005. “'Credit Cards: Facts and Theories” in G. Bertola, R. Disney and C. Grant, eds., The Economics of Consumer Credit, MIT Press, April.

Bolt, Wilko, David B. Humphrey, and Roland Uittenbogaard. 2005. "The effect of transaction pricing on the adoption of electronic payments: a cross-country comparison.” Federal Reserve Bank of Philadelphia Working Paper 05-28, November.

Borzekowski, Ron, and Elizabeth K. Kiser. 2006. "The choice at the checkout: quantifying demand across payment instruments.” Board of Governors of the Federal Reserve System Finance and Economics Discussion Series 2006-17, April.

Borzekowski, Ron, Kiser, Elizabeth K. and Ahmed, Shaista. 2006. "Consumers' Use of Debit Cards: Patterns, Preferences, and Price Response,” Board of Governors of the Federal Reserve System Finance and Economics Discussion Series 2006-16, April.

Carow, Kenneth A. and Michael E. Staten. 1999. "Debit, Credit, or Cash: Survey Evidence on Gasoline Purchases,” Journal of Economics and Business, 51(5), 409-21.

Castronova, Edward, and Paul Hagstrom. 2004. “'The Demand for Credit Cards: Evidence from the Survey of Consumer Finances,” Economic Inquiry, Vol. $42-2$ (April), pp. 304-318.

Ching, Andrew and Fumiko Hayashi. 2006. "Payment card rewards programs and consumer payment choice,” Federal Reserve Bank of Kansas City Payments System Research Working Paper, PSR WP 06-02, July.

Federal Reserve Bank of Atlanta. 1983. A Quantitative Description of the Check Collection System: A Report of Research Findings on the Check Collection System. Volumes 1 and 
2. http://www.frbatlanta.org/fi_services/1979_ckstudy/check_study.htm. Accessed February 14, 2007.

Federal Reserve Bank of Philadelphia. Consumer Payments Bibliography. http://www.philadelphiafed.org/pcc/bibliography/bibliography.pdf .

Federal Reserve System. 2007. Press Release, http://www.federalreserve.gov/newsevents/press/other/20071210a.htm.

Fusaro, Marc A. 2006. "Debit vs Credit: A Study of Self-Control in Shopping Behavior, Theory and Evidence,” Department of Economics, East Carolina University Working Paper, June.

Garcia Swartz, Daniel D., Robert W. Hahn, and Anne Layne-Farrar. 2004. "The Move Toward a Cashless Society: A Closer Look at Payment Instrument Economics,” AEI-Brookings Joint Center for Regulatory Studies Working Paper 04-20, October.

Gerdes, Geoffrey R. and Jack K. Walton II. 2002. "The Use of Checks and Other Noncash Payment Instruments in the United States," Board of Governors of The Federal Reserve System, Federal Reserve Bulletin, August.

Gerdes, Geoffrey R., May X. Liu, Darrel W. Parke, and Jack K. Walton II. 2005. "Trends in the Use of Payment Instruments in the United States,” Federal Reserve Bulletin, Spring, 180201.

Hancock, Diana and David B. Humphrey. 1998. "Payment Transactions, Instruments, and Systems: A Survey,” Journal of Banking and Finance, 21.

Hayashi, Fumiko and Elizabeth Klee. 2003. "Technology Adoption and Consumer Payments: Evidence from Survey Data,” Review of Network Economics, 2(2), June, 175-190.

Humphrey, David B., Moshe Kim, and Bent Vale. 2001. "Realizing the Gains from Electronic Payments: Costs, Pricing, and Payment Choice.” Journal of Money, Credit and Banking, Vol. 33, No. 2, Part 1, May, pp. 216-234.

Humphrey, David B., Lawrence B. Pulley, and Jukka M. Vesala. 1996. “Cash, Paper, and Electronic Payments: A Cross-Country Analysis.” Journal of Money, Credit and Banking, Vol. 28, No. 4, Part 2, November, pp. 914-939.

Jankowski, Carrie, Richard D. Porter, and Tara Rice. 2007. "Against the tide-currency use among Latin American immigrants in Chicago," Federal Reserve Bank of Chicago Economic Perspectives, vol. 31, no. 2, Q II, pp. 2-21.

Jonker, Nicole. 2005. “Payment Instruments as Perceived by Consumers - a Public Survey,” De Nederlandsche Bank Working Paper, September. 
Kim, Byoung-Min, Tansel Yilmazer, and Richard Widdows. 2006. “Adoption of Internet Banking and Consumers’ Payment Choices,” Purdue University Working Paper.

Klee, Elizabeth. 2006a. "Families' Use of Payment Instruments During a Decade of Change in the U.S. Payment System,” Finance and Economics Discussion Paper No. 2006-01, February.

. 2006b. "Paper or Plastic? The Effect of Time on the Use of Check and Debit Cards at Grocery Stores,” Finance and Economics Discussion Paper No. 2006-02, February.

Mantel, Brian. 2000. "Why Do Consumers Pay Bills Electronically? An Empirical Analysis,” Federal Reserve Bank of Chicago Economic Perspectives, 25(4), 32-48.

Mester, Loretta J. 2003. "Changes in the use of electronic means of payment: 1995-2001," Federal Reserve Bank of Philadelphia Business Review, Q3, pp. 18-20. . 2006. “Changes in the use of electronic means of payment: 1995-2004,” Federal Reserve Bank of Philadelphia Business Review, Q2, pp. 26-30.

Rysman, Marc. 2007. “An Empirical Analysis of Payment Card Usage,” Journal of Industrial Economics, LV(1), pp. 1-36.

Scholnick, Barry, Nadia Massoud, Anthony Saunders, Santiago Carbo-Valverde and Francisco Rodriguez-Fernandez (forthcoming). "The Economics of Credit Cards, Debit Cards, and ATMs: A Survey and Some New Evidence,” Journal of Banking and Finance.

Stavins, Joanna. 2001. "Effect of consumer characteristics on the use of payment instruments," Federal Reserve Bank of Boston New England Economic Review, 3Q, pp. 19-31.

Zinman, Jonathan. 2007. “Debit or Credit?” Dartmouth College, mimeo. 
Table 1: Consumer Payment Adoption Rates

\begin{tabular}{|c|c|c|c|c|c|c|c|c|c|c|c|c|c|}
\hline & & \multicolumn{2}{|c|}{ Checks } & \multicolumn{2}{|c|}{ Credit Cards } & \multicolumn{2}{|c|}{ Debit Cards } & \multicolumn{2}{|c|}{ ACH } & \multicolumn{2}{|c|}{ Online Banking } & \multicolumn{2}{|c|}{ SVC } \\
\hline & & Fed & AARP & Fed & AARP & Fed & AARP & Fed & AARP & Fed & AARP & Fed & AARP \\
\hline Total & & 99 & 81 & 86 & 45 & 67 & 43 & 71 & 49 & 49 & 28 & 35 & 14 \\
\hline \multirow{6}{*}{ Age } & Under 25 & 98 & & 87 & & 83 & & 64 & & 63 & & 41 & \\
\hline & 25-34 & 97 & 78 & 85 & 40 & 79 & 67 & 75 & 54 & 66 & 51 & 38 & 18 \\
\hline & $35-44$ & 99 & 76 & 85 & 45 & 70 & 51 & 72 & 49 & 51 & 35 & 33 & 16 \\
\hline & $45-54$ & 99 & 81 & 87 & 46 & 62 & 37 & 69 & 42 & 44 & 25 & 36 & 16 \\
\hline & 55-64 & 99 & 87 & 89 & 46 & 53 & 34 & 68 & 50 & 32 & 17 & 32 & 15 \\
\hline & 65 or Over & 100 & 86 & 100 & 47 & 53 & 22 & 70 & 49 & 29 & 8 & 41 & 8 \\
\hline \multirow{4}{*}{ Education } & HS or Less & 100 & 71 & 73 & 31 & 70 & 34 & 57 & 39 & 34 & 14 & 26 & 11 \\
\hline & Some College & 98 & 88 & 76 & 46 & 71 & 51 & 64 & 53 & 45 & 35 & 32 & 16 \\
\hline & College Degree & 99 & 88 & 90 & 60 & 68 & 51 & 75 & 58 & 52 & 43 & 37 & 15 \\
\hline & Post-Graduate School & 98 & 93 & 96 & 73 & 59 & 46 & 77 & 60 & 53 & 44 & 40 & 25 \\
\hline \multirow{4}{*}{ Income } & $<50,000$ & 98 & 77 & 73 & 35 & 73 & 39 & 61 & 39 & 44 & 19 & 31 & 14 \\
\hline & $\$ 50,000-\$ 74,999$ & 99 & 84 & 83 & 50 & 71 & 51 & 69 & 61 & 47 & 42 & 34 & 15 \\
\hline & 75,000-100,000 & 99 & 86 & 87 & 63 & 69 & 51 & 72 & 57 & 50 & 46 & 34 & 18 \\
\hline & $>100,000$ & 99 & 89 & 95 & 66 & 60 & 57 & 76 & 74 & 53 & 53 & 39 & 22 \\
\hline \multirow{2}{*}{ Homeownership } & Rent & 98 & & 77 & & 78 & & 63 & & 54 & & 32 & \\
\hline & Own & 99 & & 88 & & 64 & & 72 & & 48 & & 36 & \\
\hline
\end{tabular}

SOURCE: 2004 Boston Fed Consumer Payment Survey. 2006 Boston Fed/AARP Consumer Payment Survey.

NOTES: An adopter is defined as one who gives a positive response on survey Question 9 for a specific payment

instrument. Where no postive response was given but a number of monthly payments was indicated, the respondent was

classified as an adopter. 
Table 2: Share of Payment Instrument by Demographic Category

\begin{tabular}{|c|c|c|c|c|c|c|c|c|c|c|c|c|c|}
\hline & & \multicolumn{2}{|c|}{ Checks } & \multicolumn{2}{|c|}{ Credit Cards } & \multicolumn{2}{|c|}{ Debit Cards } & \multicolumn{2}{|c|}{ ACH } & \multicolumn{2}{|c|}{ Online Banking } & \multicolumn{2}{|c|}{ SVC } \\
\hline & & Fed & AARP & Fed & AARP & Fed & AARP & Fed & AARP & Fed & AARP & Fed & AARP \\
\hline \multicolumn{2}{|c|}{ Total } & 35 & 42 & 21 & 10 & 24 & 13 & 9 & 8 & 9 & 5 & 3 & 1 \\
\hline \multirow{6}{*}{ Age } & Under 25 & 17 & & 28 & & 34 & & 7 & & 8 & & 5 & \\
\hline & 25-34 & 24 & 22 & 24 & 7 & 30 & 25 & 8 & 8 & 12 & 10 & 3 & 1 \\
\hline & $35-44$ & 33 & 28 & 21 & 7 & 25 & 18 & 9 & 6 & 9 & 7 & 3 & 2 \\
\hline & $45-54$ & 40 & 36 & 20 & 9 & 21 & 14 & 9 & 6 & 8 & 7 & 3 & 1 \\
\hline & 55-64 & 45 & 39 & 21 & 12 & 16 & 10 & 9 & 7 & 7 & 5 & 3 & 2 \\
\hline & 65 or Over & 43 & 44 & 26 & 12 & 13 & 6 & 8 & 10 & 5 & 2 & 5 & 1 \\
\hline \multirow{4}{*}{ Education } & HS or Less & 49 & 39 & 11 & 6 & 24 & 9 & 7 & 7 & 6 & 3 & 2 & 1 \\
\hline & Some College & 40 & 37 & 13 & 8 & 28 & 15 & 8 & 8 & 8 & 7 & 3 & 2 \\
\hline & College Degree & 33 & 33 & 23 & 14 & 24 & 15 & 9 & 8 & 9 & 7 & 3 & 1 \\
\hline & Post-Graduate School & 29 & 32 & 30 & 17 & 18 & 13 & 10 & 7 & 10 & 6 & 4 & 1 \\
\hline \multirow{4}{*}{ Income } & $<50,000$ & 38 & 37 & 15 & 7 & 28 & 11 & 8 & 7 & 8 & 3 & 3 & 2 \\
\hline & $\$ 50,000-\$ 74,999$ & 37 & 34 & 17 & 11 & 26 & 16 & 8 & 8 & 8 & 8 & 3 & 1 \\
\hline & $75,000-100,000$ & 36 & 34 & 19 & 12 & 25 & 15 & 8 & 7 & 9 & 9 & 3 & 1 \\
\hline & $>100,000$ & 31 & 26 & 28 & 17 & 19 & 18 & 9 & 8 & 9 & 10 & 3 & 1 \\
\hline \multirow{2}{*}{ Homeownership } & Rent & 29 & & 20 & & 30 & & 8 & & 10 & & 3 & \\
\hline & Own & 36 & & 21 & & 22 & & 9 & & 8 & & 3 & \\
\hline
\end{tabular}

SOURCE: 2004 Boston Fed Consumer Payment Survey. 2006 Boston Fed/AARP Consumer Payment Survey.

NOTES: Share is calculated as the number of monthly payments reported for each instrument divided by the total number of monthly payments over all instruments reported in survey Question 9. Each row should sum to 100 percent. 
Table 3: Adoption Model Regressions (Logit)

\begin{tabular}{|c|c|c|c|c|c|}
\hline \multicolumn{2}{|c|}{ Explanatory Variables } & Credit Cards & Debit Cards & ACH & Online Banking \\
\hline \multirow{6}{*}{ Age } & Under 25 & 2.69 & .98 & 1.08 & 2.34 \\
\hline & $25-34$ & $.41 * * *$ & .71 & 1.19 & .97 \\
\hline & $35-44$ & .66 & .97 & 1.13 & .89 \\
\hline & $45-54$ & & & & \\
\hline & $55-64$ & $\$ 2.60$ & .82 & .54 & $.53^{*}$ \\
\hline & 65 or Over & dropped & dropped & $.04 * * *$ & .18 \\
\hline \multirow{3}{*}{ Education } & HS or Less & .84 & 1.83 & .46 & .67 \\
\hline & Some College & .81 & .92 & 1.02 & .87 \\
\hline & $\begin{array}{l}\text { College Degree } \\
\text { Post-Graduate }\end{array}$ & $2.57 * *$ & 1.21 & .96 & 96 \\
\hline \multirow{2}{*}{ Homeownership } & Own & 1.62 & $\frac{1.21}{1.15}$ & 1.48 & 1.40 \\
\hline & Rent & & & & \\
\hline \multirow{3}{*}{ Income } & $<50,000$ & .51 & .65 & $.39 * *$ & $.46^{* *}$ \\
\hline & $50,000-74,999$ & 1.00 & 1.18 & .56 & 1.07 \\
\hline & $\begin{array}{c}75,000-100,000 \\
\text { Over } 100,000\end{array}$ & 1.02 & 1.11 & .73 & .79 \\
\hline \multirow{7}{*}{$\begin{array}{l}\text { Characteristics Relative to } \\
\text { Check }\end{array}$} & Cost & $2.02 *$ & 1.04 & 1.09 & $1.88^{* *}$ \\
\hline & Ease & 1.24 & $2.45^{* *}$ & $11.76^{* * *}$ & $4.97 * * *$ \\
\hline & Safety & .93 & $2.66^{* *}$ & 1.95 & 1.47 \\
\hline & Privacy & 1.43 & .69 & .56 & 1.18 \\
\hline & Errors & 1.12 & 1.45 & 1.23 & $.61 *$ \\
\hline & Timing & $1.86 *$ & $4.22 * * *$ & $2.83 * * *$ & $4.10^{* * *}$ \\
\hline & Record & 1.10 & .65 & .63 & .98 \\
\hline \multirow{7}{*}{$\begin{array}{l}\text { Characteristics Relative to } \\
\text { Credit Cards }\end{array}$} & Cost & & $1.57^{* * *}$ & 1.10 & 1.02 \\
\hline & Ease & & .81 & .65 & .71 \\
\hline & Safety & & 1.06 & 1.01 & .92 \\
\hline & Privacy & & 1.44 & 1.10 & .95 \\
\hline & Errors & & 1.22 & 1.12 & 1.20 \\
\hline & Timing & & .85 & $.53 * * *$ & $.66^{* *}$ \\
\hline & Record & & $1.97 * * *$ & $2.47 * * *$ & .97 \\
\hline \multirow{7}{*}{$\begin{array}{c}\text { Characteristics Relative to } \\
\text { Debit Cards }\end{array}$} & Cost & 1.27 & & 1.30 & .94 \\
\hline & Ease & $1.94 *$ & & .79 & $.66^{*}$ \\
\hline & Safety & 1.15 & & .88 & 1.29 \\
\hline & Privacy & .75 & & 1.01 & 1.00 \\
\hline & Errors & 1.1 & & .91 & .82 \\
\hline & Timing & $2.04 * * *$ & & 1.29 & .87 \\
\hline & Record & 0.69 & & .88 & 1.19 \\
\hline \multirow{7}{*}{$\begin{array}{l}\text { Characteristics Relative to } \\
\text { ACH }\end{array}$} & Cost & .72 & 1.08 & & 1.12 \\
\hline & Ease & .96 & $1.89 * *$ & & 1.33 \\
\hline & Safety & 1.33 & .65 & & .98 \\
\hline & Privacy & .75 & 1.33 & & 1.14 \\
\hline & Errors & 1.11 & 1.04 & & 1.26 \\
\hline & Timing & .82 & .84 & & .78 \\
\hline & Record & 1.03 & 1.41 & & .85 \\
\hline \multirow{7}{*}{$\begin{array}{l}\text { Characteristics Relative to } \\
\text { Online Banking }\end{array}$} & Cost & 1.30 & 1.41 & 1.15 & \\
\hline & Ease & .82 & $.70^{*}$ & .73 & \\
\hline & Safety & 1.15 & .65 & .86 & \\
\hline & Privacy & .90 & 1.38 & 1.35 & \\
\hline & Errors & .96 & 1.04 & .82 & \\
\hline & Timing & .70 & $.59 * *$ & 1.07 & \\
\hline & Record & 1.38 & .91 & 1.18 & \\
\hline \multicolumn{2}{|c|}{ Number of Observations } & 1159 & 1159 & 1162 & 1162 \\
\hline
\end{tabular}

SOURCE: 2004 Boston Fed Consumer Payment Survey

NOTES: $*$ significant at $10 \%$; ${ }^{* *}$ significant at $5 \%$; ${ }^{* *}$ significant at $1 \%$. Table entries are odds ratios.

Shaded regions are reported characteristics. See text for description of sample.

|Dummy variables for each Federal Reserve District are included. 
Table 4: Use Model Regressions (OLS)

\begin{tabular}{|c|c|c|c|c|c|c|}
\hline & & Checks & Credit Cards & Debit Cards & ACH & Online Banking \\
\hline \multirow{6}{*}{ Age } & Under 25 & $-.07 * * *$ & $.08 * * *$ & .05 & -.02 & $-.05^{* *}$ \\
\hline & 25-34 & $-.04 * * *$ & $.05^{* *}$ & $.06^{* *}$ & $-.02 * * *$ & .00 \\
\hline & $35-44$ & -.01 & .00 & $.03^{* *}$ & -.01 & .00 \\
\hline & 45-54 & & & & & \\
\hline & 55-64 & -.01 & .02 & -.03 & .00 & .02 \\
\hline & 65 or Over & .06 & -.03 & -.05 & -.05 & .14 \\
\hline \multirow{4}{*}{ Education } & HS or Less & .00 & .00 & .01 & .00 & .02 \\
\hline & Some College & .00 & -.02 & .02 & $-.01 *$ & $.02 * *$ \\
\hline & College Degree & & & & & \\
\hline & Post-Graduate & $-.04 * * *$ & $.04 * * *$ & -.02 & .00 & .01 \\
\hline Homeownership & $\begin{array}{l}\text { Own } \\
\text { Rent }\end{array}$ & .01 & -.01 & -.02 & .01 & .01 \\
\hline \multirow{3}{*}{ Income } & $<50,000$ & .01 & .00 & -.02 & .01 & .02 \\
\hline & $50,000-74,999$ & .00 & .00 & -.01 & .00 & .00 \\
\hline & $\begin{array}{c}75,000-100,000 \\
\text { Over } 100,000\end{array}$ & $.02 *$ & -.01 & -.01 & .00 & -.01 \\
\hline \multirow{7}{*}{$\begin{array}{c}\text { Characteristics Relative to } \\
\text { Check }\end{array}$} & Cost & & .02 & $.03 *$ & .00 & -.01 \\
\hline & Ease & & .02 & $.08 * * *$ & $-.02 *$ & .02 \\
\hline & Safety & & 0.03 & -.02 & .01 & .00 \\
\hline & Privacy & & -.01 & -.01 & .00 & .02 \\
\hline & Errors & & $-.03 * *$ & .01 & .01 & .01 \\
\hline & Timing & & -.02 & $-.03^{*}$ & 0.01 & .01 \\
\hline & Record & & $.03 * * *$ & .01 & $.01^{* * *}$ & $.03 * * *$ \\
\hline \multirow{7}{*}{$\begin{array}{c}\text { Characteristics Relative to } \\
\text { Credit Cards }\end{array}$} & Cost & .01 & & $.05 * * *$ & .00 & .00 \\
\hline & Ease & $.05 * * *$ & & -.01 & $.02 * * *$ & -.01 \\
\hline & Safety & .01 & & .00 & .00 & .00 \\
\hline & Privacy & .01 & & -.01 & 0.01 & .00 \\
\hline & Errors & .00 & & -.01 & .00 & .01 \\
\hline & Timing & .01 & & $.03 * *$ & .00 & -.01 \\
\hline & Record & .00 & & $.03 * * *$ & .00 & .00 \\
\hline \multirow{7}{*}{$\begin{array}{c}\text { Characteristics Relative to } \\
\text { Debit Cards }\end{array}$} & Cost & $.03 * * *$ & $.04 * * *$ & & $.02 * * *$ & .00 \\
\hline & Ease & $.03 * *$ & .01 & & .01 & $.02 *$ \\
\hline & Safety & .00 & .00 & & .00 & .00 \\
\hline & Privacy & -.01 & .01 & & -.01 & .01 \\
\hline & Errors & .01 & .01 & & .00 & -.01 \\
\hline & Timing & .00 & $.02 * *$ & & $-.01 *$ & -.01 \\
\hline & Record & $.02 * * *$ & $.03 * * *$ & & $.01 *$ & .00 \\
\hline \multirow{7}{*}{$\begin{array}{c}\text { Characteristics Relative to } \\
\text { ACH }\end{array}$} & Cost & .01 & .01 & -.01 & & $.02 *$ \\
\hline & Ease & $.04 * * *$ & -.02 & -.01 & & .00 \\
\hline & Safety & .01 & .00 & .00 & & .01 \\
\hline & Privacy & -.01 & -.01 & .02 & & -.01 \\
\hline & Errors & -.01 & .00 & .01 & & .00 \\
\hline & Timing & .01 & .00 & .00 & & .01 \\
\hline & Record & .01 & .00 & .01 & & -.01 \\
\hline \multirow{7}{*}{$\begin{array}{l}\text { Characteristics Relative to } \\
\text { Online Banking }\end{array}$} & Cost & $.02 *$ & -.01 & .01 & .00 & \\
\hline & Ease & $.04 * * *$ & .01 & -.01 & .00 & \\
\hline & Safety & $.03^{* * *}$ & $-.02 * *$ & .02 & .00 & \\
\hline & Privacy & -.01 & $.03 * *$ & -.01 & .00 & \\
\hline & Errors & -.01 & .02 & .00 & .00 & \\
\hline & Timing & .00 & .01 & .01 & .01 & \\
\hline & Record & $.04 * * *$ & -.01 & .00 & -.01 & \\
\hline \multicolumn{2}{|c|}{ Number of Observations } & 1131 & 1057 & 1019 & 1038 & 951 \\
\hline
\end{tabular}

SOURCE: 2004 Boston Fed Consumer Payment Survey

NOTES: * significant at $10 \%$; ** significant at $5 \%$; *** significant at $1 \%$. Table entries are OLS coefficient estimates.

Shaded regions are reported characteristics. See text for description of sample.

|Dummy variables for each Federal Reserve District are included. 
Table 5: Change in Use Model Regressions (Ordered Logit)

\begin{tabular}{|c|c|c|c|c|c|c|}
\hline & & Checks & Credit Cards & Debit Cards & ACH & Online Banking \\
\hline \multirow{6}{*}{ Age } & Under 25 & $3.55 * * *$ & $3.34 * * *$ & .79 & $3.22 * * *$ & $6.27^{* * *}$ \\
\hline & 25-34 & 1.43 & 1.29 & .71 & 1.14 & 1.35 \\
\hline & $35-44$ & 1.13 & 1.01 & .90 & 1.13 & 1.23 \\
\hline & $45-54$ & & & & & \\
\hline & 55-64 & .72 & $1.47 *$ & .75 & 1.09 & .97 \\
\hline & 65 or Over & 5.77 & 1.74 & .33 & $.10^{*}$ & .38 \\
\hline \multirow{3}{*}{ Education } & HS or Less & 1.52 & .69 & .78 & $.53^{* *}$ & .61 \\
\hline & Some College & 1.39 & .87 & 1.32 & .76 & .99 \\
\hline & $\begin{array}{l}\text { College Degree } \\
\text { Post-Graduate }\end{array}$ & .83 & 1.02 & .85 & .93 & $1.49 *$ \\
\hline & Own & $.60 * *$ & .93 & 1.19 & 1.19 & 1.46 \\
\hline Homeownership & Rent & & & & & \\
\hline \multirow{4}{*}{ Income } & $<50,000$ & 1.61 & 1.18 & $.40^{* * *}$ & .82 & .73 \\
\hline & $50,000-74,999$ & $1.65^{*}$ & 1.09 & .78 & $1.58 * *$ & 1.39 \\
\hline & $75,000-100,000$ & 1.19 & .96 & 1.00 & $1.38^{*}$ & 1.2 \\
\hline & Over 100,000 & & & & & \\
\hline \multirow{7}{*}{$\begin{array}{c}\text { Characteristics Relative to } \\
\text { Check }\end{array}$} & Cost & & 1.18 & 1.14 & 1.15 & 1.35 \\
\hline & Ease & & 1.1 & $2.00^{* *}$ & $2.13^{* * *}$ & $4.67 * * *$ \\
\hline & Safety & & 1.03 & 1.07 & 1.08 & .64 \\
\hline & Privacy & & 1.04 & 1.04 & 1.12 & $1.83 * *$ \\
\hline & Errors & & $.70^{* *}$ & 1.28 & 1.14 & 1.06 \\
\hline & Timing & & $1.50 * *$ & $1.71 * *$ & $1.71 * * *$ & $1.88^{* * *}$ \\
\hline & Record & & 1.26 & .96 & $1.53^{* * *}$ & $1.56^{* *}$ \\
\hline \multirow{7}{*}{$\begin{array}{c}\text { Characteristics Relative to } \\
\text { Credit Cards }\end{array}$} & Cost & 1.11 & & $1.74^{* * *}$ & 1.04 & .91 \\
\hline & Ease & $1.41^{*}$ & & 1.04 & .81 & $.70 *$ \\
\hline & Safety & .94 & & 1.09 & .93 & .96 \\
\hline & Privacy & 1.04 & & 1.26 & .80 & .79 \\
\hline & Errors & .75 & & .89 & 1.07 & 1.00 \\
\hline & Timing & 1.13 & & .89 & 1.03 & .91 \\
\hline & Record & 1.04 & & $1.54 * * *$ & 1.17 & 1.05 \\
\hline \multirow{7}{*}{$\begin{array}{c}\text { Characteristics Relative to } \\
\text { Debit Cards }\end{array}$} & Cost & $1.46^{* *}$ & $1.75^{* * *}$ & & 1.12 & 1.02 \\
\hline & Ease & 1.03 & 1.20 & & 1.29 & .73 \\
\hline & Safety & 1.13 & .98 & & 1.02 & 1.11 \\
\hline & Privacy & 1.05 & 1.14 & & 1.21 & 1.17 \\
\hline & Errors & 1.36 & 1.16 & & .90 & .90 \\
\hline & Timing & .93 & 1.16 & & 1.02 & .88 \\
\hline & Record & 1.23 & 1.18 & & .85 & 1.19 \\
\hline \multirow{7}{*}{$\begin{array}{c}\text { Characteristics Relative to } \\
\text { ACH }\end{array}$} & Cost & $1.61^{* * *}$ & 1.09 & .88 & & $1.50^{* *}$ \\
\hline & Ease & 1.25 & .85 & .82 & & .95 \\
\hline & Safety & 1.04 & 1.01 & .86 & & .98 \\
\hline & Privacy & 1.12 & 1.02 & 1.04 & & 1.01 \\
\hline & Errors & 1.08 & .93 & 1.19 & & 1.16 \\
\hline & Timing & 1.08 & .97 & 1.12 & & .91 \\
\hline & Record & 1.05 & 1.04 & 1.23 & & $.74 *$ \\
\hline \multirow{7}{*}{$\begin{array}{c}\text { Characteristics Relative to } \\
\text { Online Banking }\end{array}$} & Cost & 1.03 & $.79 * *$ & 1.22 & .83 & \\
\hline & Ease & $1.68^{* * *}$ & 1.08 & .89 & 1.02 & \\
\hline & Safety & .98 & .95 & 1.11 & 1.09 & \\
\hline & Privacy & 1.31 & .94 & .89 & .98 & \\
\hline & Errors & 1.05 & $1.34^{* *}$ & .98 & .88 & \\
\hline & Timing & 1.02 & .82 & .83 & $.77 *$ & \\
\hline & Record & $1.40^{*}$ & 1.00 & .92 & .88 & \\
\hline \multicolumn{2}{|c|}{ Number of Observations } & 1112 & 1096 & 1075 & 1072 & 1045 \\
\hline
\end{tabular}

SOURCE: 2004 Boston Fed Consumer Payment Survey

NOTES: * significant at $10 \%$; ** significant at $5 \%$; ** significant at $1 \%$. Table entries are odds ratios.

Shaded regions are reported characteristics. See text for description of sample.

For the dependent variables, 1 represents an increase in use, 0 represents no change, and -1 represents a decrease.

|Dummy variables for each Federal Reserve District are included. 
Table 6: Switch Payment Method Model Regressions (Logit)

\begin{tabular}{|c|c|c|c|c|c|}
\hline & & Credit Cards & Debit Cards & ACH & Online Banking \\
\hline \multirow{6}{*}{ Age } & Under 25 & .62 & $.27^{* *}$ & .62 & .59 \\
\hline & 25-34 & .69 & .61 & .95 & 1.27 \\
\hline & $35-44$ & .74 & .8 & 1.08 & .76 \\
\hline & $45-54$ & & & & \\
\hline & 55-64 & 1.65 & .55 & .68 & $.48^{* *}$ \\
\hline & 65 or Over & .14 & .25 & $.01 * * *$ & $.02 * *$ \\
\hline \multirow{3}{*}{ Education } & HS or Less & 1.14 & 1.52 & .65 & 1.59 \\
\hline & Some College & 1.15 & 1.09 & .80 & 1.15 \\
\hline & $\begin{array}{l}\text { College Degree } \\
\text { Post-Graduate }\end{array}$ & 1.15 & .86 & 1.01 & 1.25 \\
\hline Homeownership & $\begin{array}{l}\text { Own } \\
\text { Rent }\end{array}$ & 1.52 & 1.02 & $2.31^{* * *}$ & 1.57 \\
\hline \multirow{3}{*}{ Income } & $<50,000$ & .57 & 1.13 & 1.02 & $.57 *$ \\
\hline & $50,000-74,999$ & .62 & 1.19 & .99 & 1.02 \\
\hline & 75,000-100,000 & .63 & .85 & .94 & $.56^{* *}$ \\
\hline \multirow{7}{*}{$\begin{array}{c}\text { Characteristics Relative } \\
\text { to Check }\end{array}$} & Cost & $217 * * *$ & 115 & 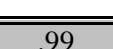 & $\overline{185 * *}$ \\
\hline & Ease & 1.03 & 1.75 & $4.02^{* * *}$ & $2.35^{* *}$ \\
\hline & Safety & .85 & 1.87 & .97 & $2.28 * *$ \\
\hline & Privacy & .93 & .61 & .86 & .69 \\
\hline & Errors & 1.28 & $1.74^{*}$ & 1.2 & .93 \\
\hline & Timing & $2.28 * * *$ & $2.80 * * *$ & $3.29 * * *$ & $2.76^{* * *}$ \\
\hline & Record & .96 & .67 & .78 & .81 \\
\hline \multirow{7}{*}{$\begin{array}{l}\text { Characteristics Relative } \\
\text { to Credit Cards }\end{array}$} & Cost & & $1.35^{* *}$ & .90 & 1.06 \\
\hline & Ease & & .78 & .91 & 1.01 \\
\hline & Safety & & 1.14 & .95 & .86 \\
\hline & Privacy & & $1.88 * * *$ & 1.12 & .98 \\
\hline & Errors & & .80 & .89 & 1.18 \\
\hline & Timing & & 1.04 & $.71^{*}$ & 1.05 \\
\hline & Record & & $2.08 * * *$ & $1.86^{* * *}$ & 1.02 \\
\hline \multirow{7}{*}{$\begin{array}{l}\text { Characteristics Relative } \\
\text { to Debit Cards }\end{array}$} & Cost & .99 & & 1.28 & .82 \\
\hline & Ease & 1.32 & & .93 & .84 \\
\hline & Safety & $1.41^{*}$ & & .96 & 1.25 \\
\hline & Privacy & .82 & & 1.22 & 1.21 \\
\hline & Errors & .94 & & 1.02 & .83 \\
\hline & Timing & 1.11 & & .87 & .92 \\
\hline & Record & .97 & & $.71^{*}$ & .99 \\
\hline \multirow{7}{*}{$\begin{array}{c}\text { Characteristics Relative } \\
\text { to } \mathrm{ACH}\end{array}$} & Cost & .85 & 1.20 & & 1.26 \\
\hline & Ease & 1.25 & $2.90 * * *$ & & $1.54 *$ \\
\hline & Safety & 1.35 & .81 & & .99 \\
\hline & Privacy & 1.24 & 1.17 & & $1.48^{*}$ \\
\hline & Errors & .72 & .75 & & .75 \\
\hline & Timing & $1.52^{* *}$ & 1.13 & & 1.05 \\
\hline & Record & 1.06 & 1.23 & & .80 \\
\hline \multirow{7}{*}{$\begin{array}{l}\text { Characteristics Relative } \\
\text { to Online Banking }\end{array}$} & Cost & 1.09 & 1.35 & 1.05 & \\
\hline & Ease & 1.05 & .72 & .87 & \\
\hline & Safety & 1.13 & .71 & .81 & \\
\hline & Privacy & .75 & 1.04 & .96 & \\
\hline & Errors & 1.38 & 1.29 & $1.55^{*}$ & \\
\hline & Timing & $.52 * * *$ & $.57^{* *}$ & .72 & \\
\hline & Record & 1.18 & 1.08 & 1.47 & \\
\hline \multicolumn{2}{|c|}{ Number of Observations } & 1163 & 11162 & 1162 & 1162 \\
\hline
\end{tabular}

SOURCE: 2004 Boston Fed Consumer Payment Survey

NOTES: * significant at $10 \%$; ** significant at $5 \%$; *** significant at $1 \%$. Table entries are odds ratios.

Shaded regions are reported characteristics. See text for description of sample

|Dummy variables for each Federal Reserve District are included. 


\section{Table 7: Model Evaluation Statistics}

Model Fit (Pseudo $\mathbf{R}^{\wedge}$ 2)

\begin{tabular}{|c|l|c|c|c|c|}
\hline \multirow{5}{*}{ Model } & \multirow{3}{*}{} & & \multicolumn{3}{|c|}{ Restricted Models } \\
\cline { 3 - 6 } Adoption & Payment Method & Full Model & $\begin{array}{c}\text { Reported CHAR } \\
\text { only }\end{array}$ & $\begin{array}{c}\text { Derived CHAR } \\
\text { only }\end{array}$ & DEM \& MD only \\
\hline \multirow{3}{*}{ Use } & Credit Card & .31 & .17 & .17 & .14 \\
& Debit Card & .37 & .29 & .24 & .03 \\
& ACH & .43 & .34 & .22 & .08 \\
& Online Banking & .37 & .31 & .17 & .06 \\
\hline \multirow{5}{*}{} & Check & .37 & -- & .33 & .09 \\
& Credit Card & .25 & .12 & .18 & .08 \\
& Debit Card & .2 & .07 & .14 & .07 \\
& ACH & .12 & .04 & .07 & .03 \\
& Online Banking & .11 & .06 & .06 & .03 \\
\hline
\end{tabular}

\section{Coefficient Restriction Tests (p-value)}

\begin{tabular}{|c|l|c|c|c|}
\hline \multirow{5}{*}{ Model } & & \multicolumn{3}{|c|}{ Coefficients excluded from Full Model } \\
\cline { 3 - 5 } & Payment Method & DEM \& MD & Derived CHAR & $\begin{array}{c}\text { Derived and } \\
\text { Reported CHAR }\end{array}$ \\
\hline \multirow{5}{*}{ Adoption } & Credit Card & .00 & .12 & .00 \\
& Debit Card & .72 & .00 & .00 \\
& ACH & .03 & .23 & .00 \\
& Online Banking & .19 & .24 & .00 \\
\hline \multirow{5}{*}{ Use } & Check & .00 & .00 & -- \\
& Credit Card & .00 & .00 & .00 \\
& Debit Card & .00 & .00 & .00 \\
& ACH & .07 & .00 & .00 \\
& Online Banking & .17 & .45 & .00 \\
\hline
\end{tabular}

SOURCE: 2004 Boston Fed Consumer Payment Survey

NOTES: \# of observations in adoption model range from 1159-1162. \# of observations in use model range from 951-1131. 
Table 8

Effects of Payment Characteristics on Consumer Characteristics

\begin{tabular}{|c|c|c|c|c|c|c|c|c|c|c|c|}
\hline \multirow{2}{*}{\multicolumn{2}{|c|}{ Adoption }} & \multicolumn{2}{|c|}{ Check } & \multicolumn{2}{|c|}{ Credit Cards } & \multicolumn{2}{|c|}{ Debit Cards } & \multicolumn{2}{|c|}{$\mathrm{ACH}$} & \multicolumn{2}{|c|}{ OB } \\
\hline & & (1) & (2) & (1) & (2) & (1) & (2) & (1) & (2) & (1) & (2) \\
\hline \multirow{6}{*}{ Age } & Under 25 & & & $3.75^{*}$ & 2.69 & 1.71 & .98 & $3.30^{*}$ & 1.08 & $8.27 * * *$ & 2.34 \\
\hline & 25-34 & & & .63 & $.41 * * *$ & 1.04 & .71 & 1.50 & 1.19 & $1.85^{* * *}$ & .97 \\
\hline & $35-44$ & & & .72 & .66 & 1.07 & .97 & 1.15 & 1.13 & 1.10 & .89 \\
\hline & $45-54$ & & & & & & & & & & \\
\hline & 55-64 & & & 1.86 & 2.60 & .64 & .82 & .60 & .54 & $.50 * *$ & $.53 *$ \\
\hline & 65 or Over & & & & dropped & & dropped & .13 & $.04^{* * *}$ & .37 & 18 \\
\hline \multirow{3}{*}{ Education } & HS or Less & & & .61 & .84 & $2.91 *$ & 1.83 & $.48^{* *}$ & .46 & .74 & .67 \\
\hline & Some College & & & $.58 * *$ & .81 & 1.32 & .92 & .95 & 1.02 & .89 & .87 \\
\hline & $\begin{array}{l}\text { College Degree } \\
\text { Post-Graduate }\end{array}$ & & & $3.78 * * *$ & $2.57 * *$ & 1.14 & 1.21 & 1. & .96 & 122 & 96 \\
\hline \multirow{2}{*}{ Homeownership } & Own & & & $1.69 *$ & 1.62 & .84 & 1.15 & $1.93 * *$ & 1.48 & 1.26 & 1.40 \\
\hline & Rent & & & & & & & & & & \\
\hline \multirow{4}{*}{ Income } & $<50,000$ & & & $.34 * * *$ & .51 & $.51^{* *}$ & .65 & $.35 * * *$ & $.39 * *$ & $.38 * * *$ & $.46^{* *}$ \\
\hline & $50,000-74,999$ & & & .75 & 1.00 & 1.13 & 1.18 & $.59 *$ & .56 & .87 & 1.07 \\
\hline & $75,000-100,000$ & & & .86 & 1.02 & .97 & 1.11 & .79 & .73 & .94 & .79 \\
\hline & Over 100,000 & & & & & & & & & & \\
\hline
\end{tabular}

\begin{tabular}{|c|c|c|c|c|c|c|c|c|c|c|c|}
\hline \multirow{2}{*}{\multicolumn{2}{|c|}{ Use }} & \multicolumn{2}{|c|}{ Check } & \multicolumn{2}{|c|}{ Credit Cards } & \multicolumn{2}{|c|}{ Debit Cards } & \multicolumn{2}{|c|}{$\mathrm{ACH}$} & \multicolumn{2}{|c|}{ OB } \\
\hline & & $(1)$ & (2) & (1) & $(2)$ & (1) & $(2)$ & (1) & (2) & (1) & (2) \\
\hline \multirow{6}{*}{ Age } & Under 25 & -.17 & $-.07 * * *$ & $.09 * * *$ & $.08 * * *$ & .05 & .05 & -.02 & -.02 & -.04 & $-.05^{* *}$ \\
\hline & 25-34 & $-.08 * * *$ & $-.04 * * *$ & $.05^{* * *}$ & $.05^{* *}$ & $.06^{* * *}$ & $.06 * *$ & -.02 & $-.02 * * *$ & .01 & .00 \\
\hline & $35-44$ & -.02 & -.01 & .01 & .00 & $.03^{*}$ & $.03 * *$ & -.01 & -.01 & .00 & .00 \\
\hline & $45-54$ & & & & & & & & & & \\
\hline & $55-64$ & .03 & -.01 & .03 & .02 & -.04 & -.03 & .00 & .00 & .02 & .02 \\
\hline & 65 or Over & 12 & .06 & -.05 & -.03 & -.10 & -.05 & -.03 & -.05 & .14 & .14 \\
\hline \multirow{3}{*}{ Education } & HS or Less & .00 & .00 & -.04 & .00 & .01 & .01 & .00 & .00 & .02 & .02 \\
\hline & Some College & .00 & .00 & -.04 & -.02 & .03 & .02 & -.01 & $-.01^{*}$ & $.03 * *$ & $.02 * *$ \\
\hline & Post-Graduate & -.05 & $-.04 * * *$ & $.05 * * *$ & $.04^{* * *}$ & -.03 & -.02 & .00 & .00 & 01 & 01 \\
\hline & Own & .00 & .01 & -.01 & -.01 & -.02 & -.02 & .01 & .01 & .00 & .01 \\
\hline Homeownership & Rent & & & & & & & & & & \\
\hline \multirow{4}{*}{ Income } & $<50,000$ & $.07 * * *$ & .01 & -.01 & .00 & .00 & -.02 & $.02 *$ & .01 & .01 & .02 \\
\hline & $50,000-74,999$ & .02 & .00 & -.02 & .00 & -.01 & -.01 & .01 & .00 & .00 & .00 \\
\hline & $75,000-100,000$ & $.03 * *$ & $.02 *$ & -.01 & -.01 & .00 & -.01 & .00 & .00 & -.01 & -.01 \\
\hline & Over 100,000 & & & & & & & & & & \\
\hline
\end{tabular}

SOURCE: 2004 Boston Fed Consumer Payment Survey.

NOTES: * significant at $10 \%$; ** significant at $5 \%$; ** significant at $1 \%$. Adoption table entries are odds ratios. Use table entries are OLS coefficient estimates. Model 1 includes only demographics. Model 2 is the full model, including demographics and reported and derived characteristics.

Dummy variables for each Federal Reserve District are included in both models. 


\section{Figure 1}

\section{Total U.S. Volume of Paper Checks}

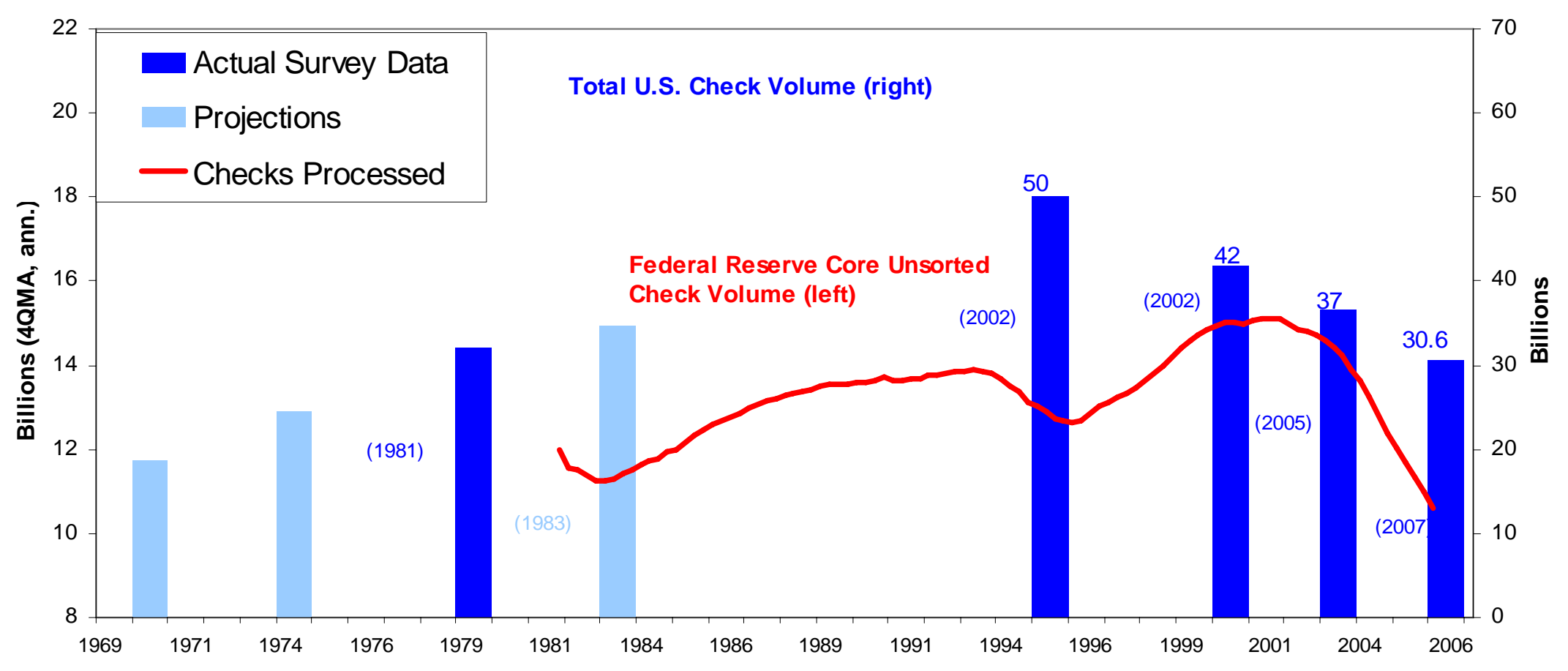

NOTES: Numbers in parentheses are the years the data were published.

SOURCES: Federal Reserve Bank of Atlanta (1981, 1983); Federal Reserve System (2002, 2004); Gerdes and Walton (2002); Gerdes, Liu, Parke, and Walton (2005); Benton, Blair, Crowe, and Schuh (2007). 
Figure 2

\section{U.S. Payment Adoption Rates (Consumers Only)}

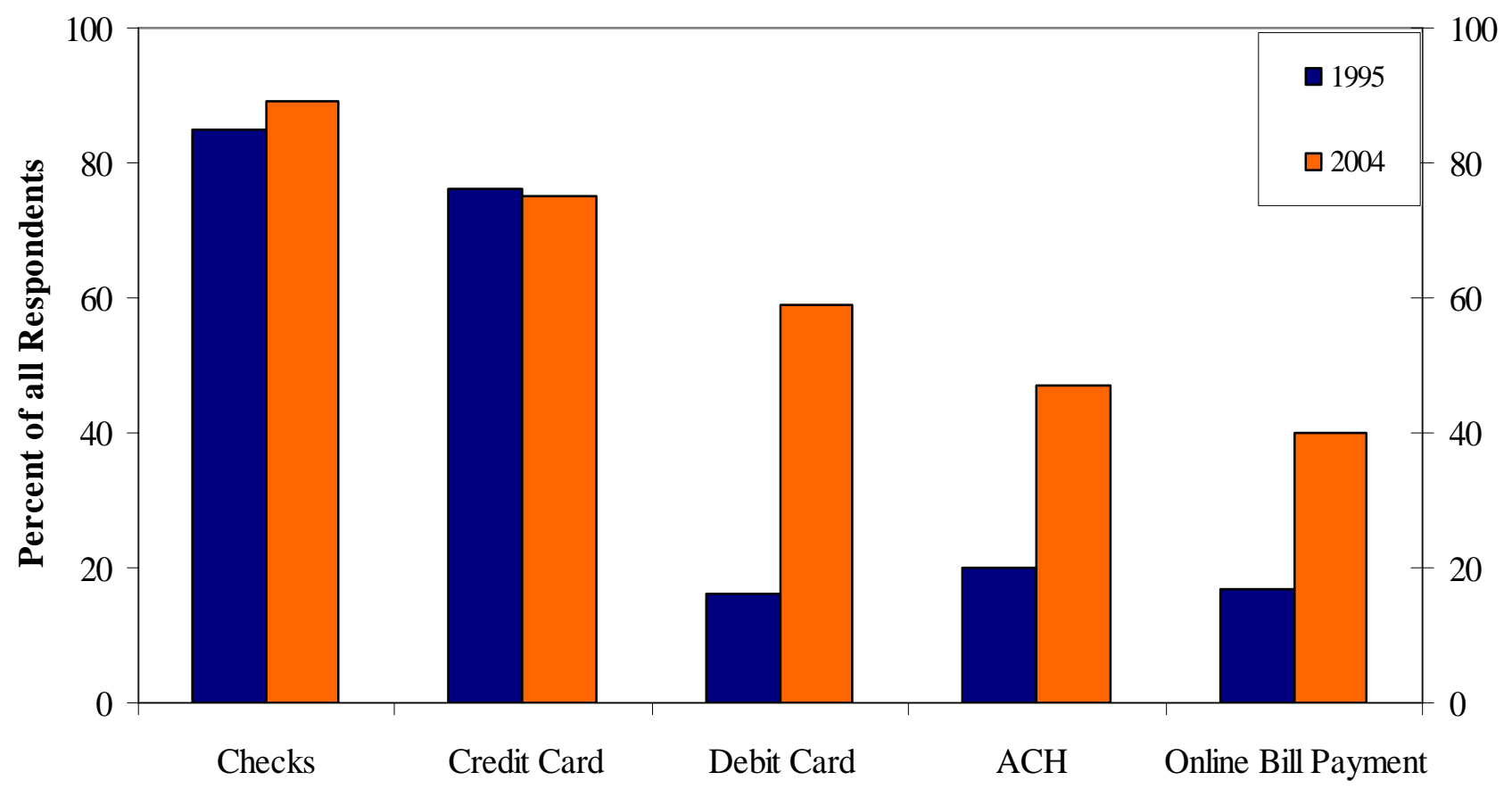

U.S. Payment Use (All)

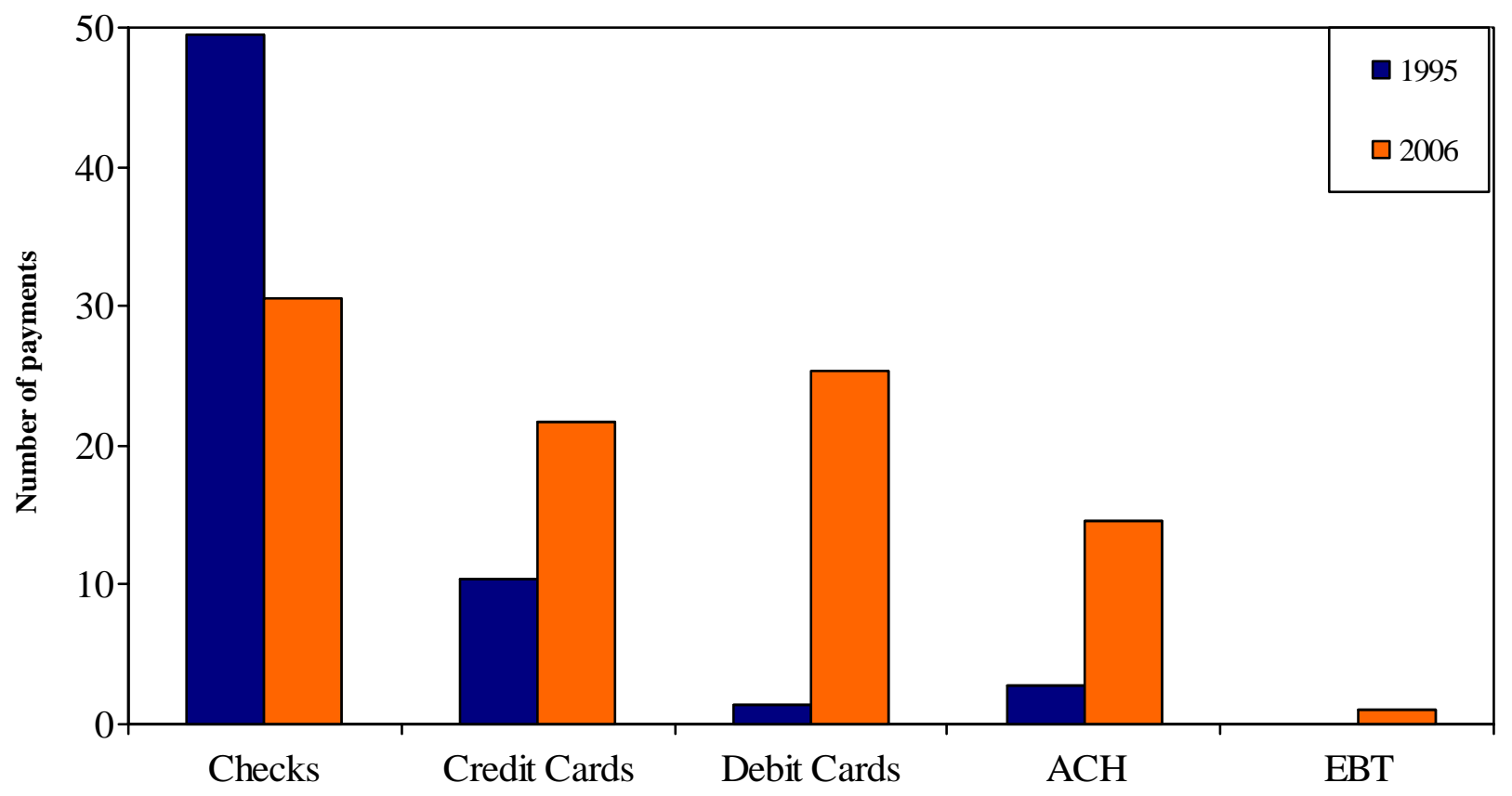

SOURCES: Top Panel: Survey of Consumer Finance (1995, 2004).

Bottom Panel: Gerdes et al (2002), 2007 Federal Reserve Payments Study. 
Figure 3

Possible Values of Derived Payment Characteristics

Value of reported characteristics (relative to check for payment instrument j)

Value of reported characteristics (relative to check for payment instrument j')

$-1$

0

1

\begin{tabular}{|c|c|c|c|}
\cline { 2 - 4 }-1 & 0 & 1 & 2 \\
\cline { 2 - 4 } 0 & -1 & 0 & 1 \\
\hline 1 & -2 & -1 & 0 \\
\hline
\end{tabular}

Values in table are the difference between column values and row values. See text for derivation. 
Figure 4

Comparison of Fed and AARP Survey Data

Adoption Rates

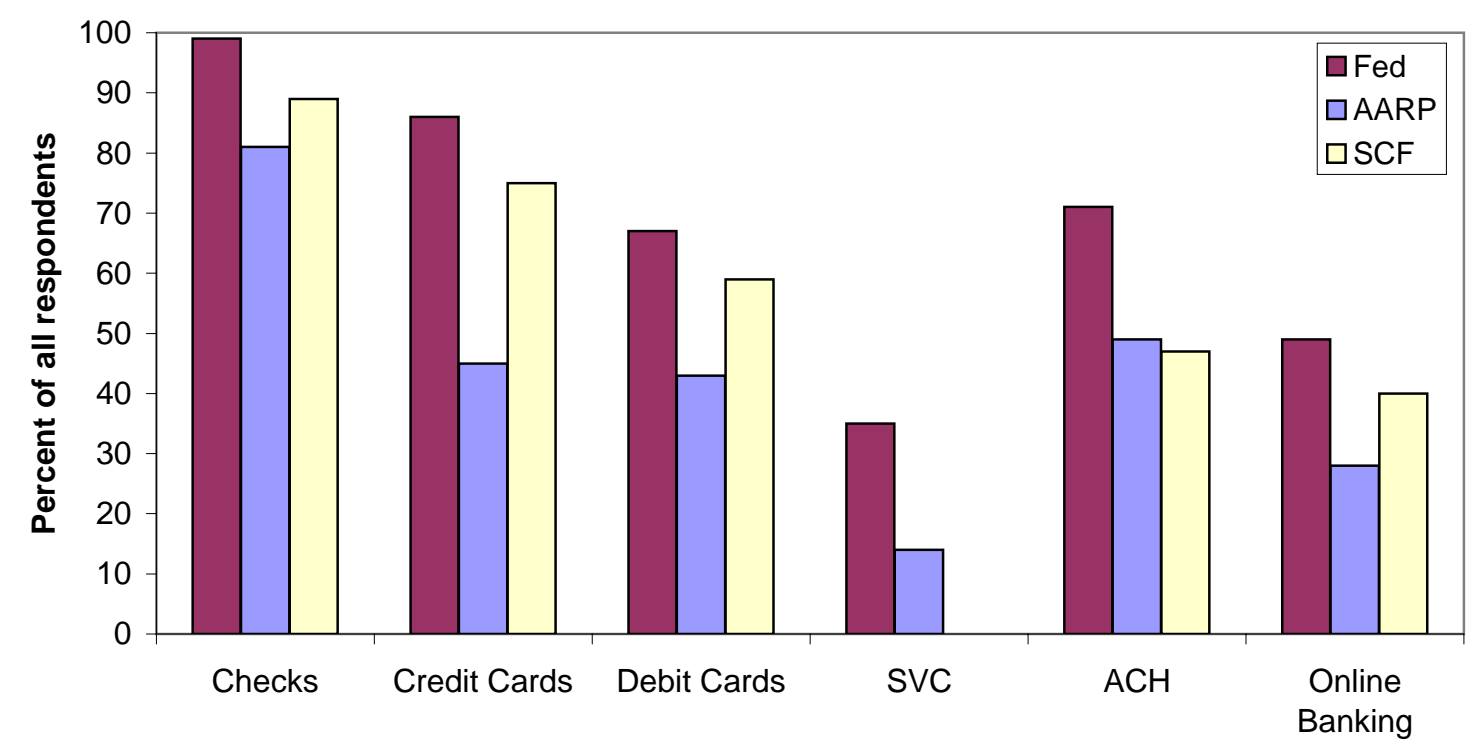

Payment Use by Adopters

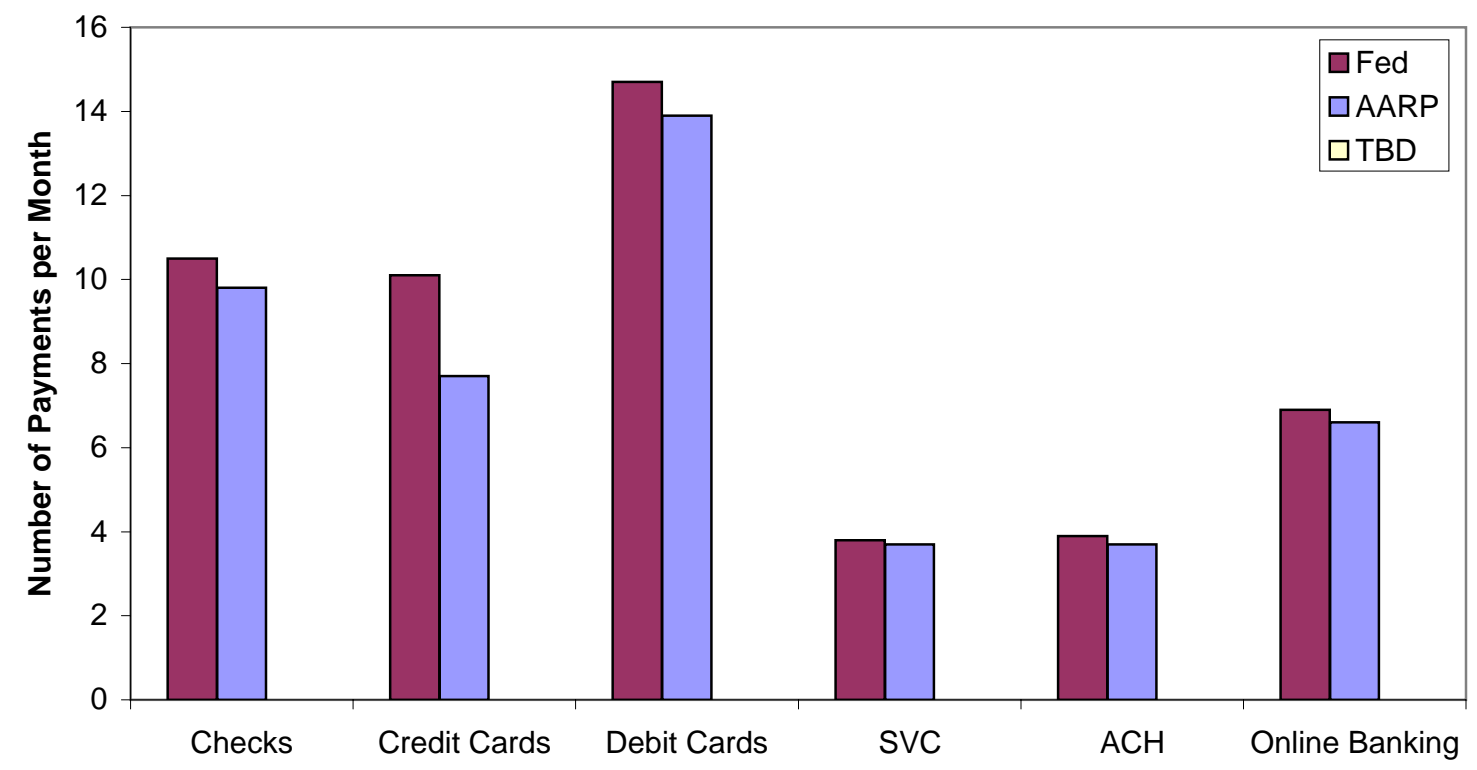

SOURCES: Top Panel: Survey of Consumer Finance (2004), 2004 Boston Fed Consumer Payment Survey, 2006 Boston Fed/AARP Consumer Payment Survey.

Bottom Panel: 2004 Boston Fed Consumer Payment Survey, 2006 Boston Fed/AARP Consumer Payment Survey. NOTES: SVC data not available from the SCF. 